Zhu, C., Cotton, F., Kwak, D.-Y., Ji, K., Kawase, H., Pilz, M. (2022): Within-site variability in earthquake site response. Geophysical Journal International, 229, 2, 1268-1281.

https://doi.org/10.1093/gji/ggab481 


\title{
Within-site variability in earthquake site response
}

\author{
Chuanbin Zhu ${ }^{\odot},{ }^{1}$ Fabrice Cotton, ${ }^{1,2}$ Dong-Youp Kwak, ${ }^{3}$ Kun Ji, ${ }^{4}$ Hiroshi Kawase ${ }^{5}$ and \\ Marco Pilz ${ }^{\oplus 1}$ \\ ${ }^{1}$ Helmholtz Centre Potsdam - GFZ German Research Centre for Geosciences, 14473 Potsdam, Germany. E-mail: chuanbin.zhu@hdr.qut.edu.au \\ ${ }^{2}$ University of Potsdam, Institute of Geosciences, Campus Golm / Building 27 Karl-Liebknecht-Str. 24-25, 14476 Potsdam, Germany \\ ${ }^{3}$ Department of Civil and Environmental Engineering, Hanyang University, 15588, Ansan, Korea \\ ${ }^{4}$ China Earthquake Administration, Institute of Engineering Mechanics, 150080, Harbin, China \\ ${ }^{5}$ Kyoto University, Disaster Prevention Research Institute, 611-0011, Kyoto, Japan
}

Accepted 2021 November 21. Received 2021 October 12; in original form 2021 June 3

\begin{abstract}
SUMMAR Y
The within-site variability in site response is the randomness in site response at a given site from different earthquakes and is treated as aleatory variability in current seismic hazard/risk analyses. In this study, we investigate the single-station variability in linear site response at KNET and KiK-net stations in Japan using a large number of earthquake recordings. We found that the standard deviation of the horizontal-to-vertical Fourier spectral ratio at individual sites, that is single-station horizontal-to-vertical spectral ratio (HVSR) sigma $\sigma_{\mathrm{HV}, \mathrm{s}}$, approximates the within-site variability in site response quantified using surface-to-borehole spectral ratios (for oscillator frequencies higher than the site fundamental frequency) or empirical groundmotion models. Based on this finding, we then utilize the single-station HVSR sigma as a convenient tool to study the site-response variability at $697 \mathrm{KiK}-$ net and $1169 \mathrm{~K}-\mathrm{NET}$ sites. Our results show that at certain frequencies, stiff, rough and shallow sites, as well as small and local events tend to have a higher $\sigma_{\mathrm{HV}, \mathrm{s}}$. However, when being averaged over different sites, the single-station HVSR sigma, that is $\sigma_{\mathrm{HV}}$, increases gradually with decreasing frequency. In the frequency range of $0.25-25 \mathrm{~Hz}, \sigma_{\mathrm{HV}}$ is centred at $0.23-0.43$ in ln scales (a linear scale factor of 1.26-1.54) with one standard deviation of less than 0.1. $\sigma_{\mathrm{HV}}$ is quite stable across different tectonic regions, and we present a constant, as well as earthquake magnitude- and distance-dependent $\sigma_{\mathrm{HV}}$ models.
\end{abstract}

Key words: Earthquake ground motions; Earthquake hazards; Site effects.

\section{INTRODUCTION}

In probabilistic seismic hazard analyses (PSHA), the variability/uncertainty of site response includes between-site (also called intersite or site-to-site) and within-site (intrasite or single-site) variability. Herein we refer to the between-site variability as the spatial variability in the average site response (over multiple events) across many sites in a data set, and it depends on the spatial scale of the study region and the complexity of the surface geology in that region. In empirical ground-motion models (GMMs, e.g. Abrahamson et al. 2014; Boore et al. 2014), it often appears in the form of site-to-site variability in the site term which is the repeatable site response uncaptured by the proxy-based 'GMM-native' amplification models (Al Atik et al. 2010). Though this variability is epistemic uncertainty which is due to the lack of knowledge and is reducible, it is often treated as aleatory variability (natural randomness in a process and irreducible) under ergodic assumptions and contributes to the total uncertainty in ground-motion estimates (e.g. Lin et al.
2011). In a site-specific PSHA, between-site variability can be fully or partially removed (Atkinson 2006; Morikawa et al. 2008).

In contrast, the within-site variability is defined as the randomness in site response from event to event at a single site, and it is considered to be aleatory. The within-site variability in site response arises from (i) the randomness in azimuth, incident angle and composition of wave fields (e.g. SH, $P-\mathrm{SV}$ and surface waves) of input motions (e.g. Bowden \& Tsai 2017; Maufroy et al. 2017); (ii) the spatially variable nature of a site, that is surface and subsurface topography (e.g. Matsushima et al. 2017; Wirth et al. 2019) and (iii) the temporally variable nature of soil properties due to soil non-linearity or meteorological factors, for example rainfall and temperature (e.g. Roumelioti et al. 2019; Bonilla \& Ben-Zion 2021). The above factors are not completely independent. For instance, the lateral variability of material properties at a certain site can interact with the variability in azimuth and incident angle of incoming waves, together contributing to the randomness in site response at the site. 
The between-site variability in site response has been extensively investigated in many preceding studies on GMMs (e.g. Bindi et al. 2017; Kotha et al. 2018). However, the within-site variability in site response has received far less attention. This is partly because, under the GMM framework, quantifying the randomness in site response necessitates single-path analyses which require repeated observations along the same wave propagation path (e.g. Lin et al. 2011). Other reference approaches, that is surface-to-borehole spectral ratio (SBSR) or standard spectral ratio (SSR), need multiple events simultaneously recorded at both collocated surface-downhole pairs for the former, and at the ground surface and nearby outcrop rock sites for the latter. Zhao et al. (2009) and Zhao \& Zhang (2010) utilized numerical simulations to investigate the dependence of siteresponse variability on earthquake scenarios.

In this study, we capitalize on the large volume of accelerograms accumulated at K-NET and KiK-net strong-motion stations in Japan (NIED 2019) and utilize the horizontal-to-vertical spectral ratio (HVSR) technique to investigate the randomness in site response at individual sites. We first present the within-site variability in site response quantified using SBSR and GMMs Then we study the within-site variability using HVSR at $697 \mathrm{KiK}-$ net and $1169 \mathrm{~K}-\mathrm{NET}$ sites. This is followed by a thorough examination of its dependence on site conditions (30 m average shear wave velocity, site resonant frequency, sediment thickness, surface roughness and geomorphology), earthquake scenarios (earthquake magnitude, as well as source-site distance and azimuth) and tectonic regions. Implications of this research on 1-D ground response analyses (GRA) and event-specific amplification predictions are discussed.

\section{WITHIN-SITE VARIABILITY IN SITE RESPONSE}

\section{Surface-to-borehole spectral ratio}

For a collocated surface-downhole site $s$, its SBSR from an earthquake $e$ is computed as the ratio of the response ( 5 per cent-damped PSA) or smoothed Fourier amplitude (FAS) spectrum (using KonnoOhmachi [1998] window with a smoothing coefficient $b=20$ ) at the ground surface to that at the downhole. SBSR is computed for the two horizontal components (NS and EW) separately and then is combined via their arithmetic mean in natural logarithmic scale:

$\ln \mathrm{SBSR}_{e s}=\frac{\ln \mathrm{SBSR}_{e s, \mathrm{NS}}+\ln \mathrm{SBSR}_{e s, \mathrm{EW}}}{2}$.

If the surface-downhole site $s$ has many recordings (at least three), its $\ln \mathrm{SBSR}_{e s}$ s are considered to be normally distributed and can be described by its mean over many earthquakes $\ln S B S R_{s}$ and its standard deviation $\sigma_{\mathrm{SB}, \mathrm{s}}$ (SBSR sigma) which represents the site response variability at site $s$ :

$\ln \mathrm{SBSR}_{e s}=\ln \mathrm{SBSR}_{\mathrm{s}}+\varepsilon_{\mathrm{SB}, e s} \sigma_{\mathrm{SB}, s}$,

where $\varepsilon_{S B, e s}$ represents the deviation of $\ln \mathrm{SBSR}_{e s}$ for the event $e$ from the mean in terms of number of standard deviations and is a standard normal random variable (Fig. 1a). All the terms in eqs (1) and (2) are frequency-dependent, but oscillator frequency $f$ is omitted for brevity. The average of $\sigma_{\mathrm{SB}, \mathrm{s}}$ across many sites is denoted as $\sigma_{\mathrm{SB}}$ as illustrated in Fig. 1(b) for $207 \mathrm{KiK}$-net sites selected by Zhu et al. (2019) as having downhole velocity larger than $800 \mathrm{~m} \mathrm{~s}^{-1}$ and borehole deeper than $100 \mathrm{~m}$. Earthquake recordings were selected from the Dawood et al. (2016) ground-motion database, excluding those affected by soil non-linearity. Fig. 1(b) shows a rather small
$\sigma_{\mathrm{SB}, \mathrm{s}}$ at low frequencies, and this is caused by the relatively limited borehole depth as later explained in the descriptions to Figs 2 and 3.

\section{Ground motion model (GMM)}

In addition to SBSR, the single-station site response variability can also be quantified in empirical ground motion modellings. Adapted from the notation used by Al Atik et al. (2010) and RodríguezMarek et al. (2011), for a single-path data set, the total residual $\left(\Delta_{e s}^{S}\right)$ of surface ground motion between observation and prediction from GMM can be portioned into the event $\left(\delta B_{e}\right)$, path $\left(\delta P 2 P_{s l}^{S}\right)$ and site terms $\left(\delta S 2 S_{s}^{S}\right)$, as well as the remaining unexplained residual term $\left(\delta W_{0, e s l}^{S}\right)$ :

$\Delta_{e s}^{S}=\delta B_{e}+\delta S 2 S_{s}^{S}+\delta P 2 P_{s l}^{S}+\delta W_{0, e s l}^{S}$,

where subscript $S$ represents relevant components for surface recordings. If recordings from collocated downhole sensors are available, the total residual can be written as:

$\Delta_{e s}^{S}=\Delta_{e s}^{B}+\Delta A m p_{e s}$,

where subscript $B$ denotes corresponding components for borehole recordings; $\Delta_{e s}^{B}$ is the total ground-motion residual at borehole and $\triangle A m p_{e s}$ is total residual between observed and predicted site amplifications from the ground surface to borehole depth. Similar to $\Delta_{e s}^{S}$ in eq. (3), $\Delta_{e s}^{B}$ can be further portioned into different components in eq. (5). $\Delta A m p_{e s}$ can also be separated into a systematic component $\delta S 2 S_{s}^{A m p}$ and an event-specific residual term $\delta A m p_{e s}$ in eq. (6). The relationship between the site terms for the ground surface and the downhole is expressed in eq. (7).

$\Delta_{e s}^{B}=\delta B_{e}+\delta S 2 S_{s}^{B}+\delta P 2 P_{s l}^{B}+\delta W_{0, e s l}^{B}$,

$\Delta A m p_{e s}=\delta S 2 S_{s}^{A m p}+\delta A m p_{e s}$,

$\delta S 2 S_{s}^{A m p}=\delta S 2 S_{s}^{S}-\delta S 2 S_{s}^{B}$,

Substituting eqs (5)-(7) into eq. (4), we can obtain the following equation:

$\Delta_{e s}^{S}=\delta B_{e}+\delta S 2 S_{s}^{S}+\delta A m p_{e s}+\delta P 2 P_{s l}^{B}+\delta W_{0, e s l}^{B}$,

Comparing eqs (3) and (8), we can derive

$\delta W_{0, e s l}^{S}=\delta A m p_{e s}-\left(\delta P 2 P_{s l}^{S}-\delta P 2 P_{s l}^{B}\right)+\delta W_{0, e s l}^{B}$.

Rodríguez-Marek et al. (2011) developed empirical GMMs using data from KiK-net surface-downhole pairs in Japan and quantified the within-site variability of site response $\phi_{S S}^{A m p}$, that is the standard deviation of $\delta A m p_{e s}$ in eq. (8). Lin et al. (2011) conducted single-path analyses to surface recordings from Taiwan and derived the event- and path-corrected single-station standard deviation $\phi_{s s}$, namely the standard deviation of $\delta W_{0, e s l}^{S}$ in eq. (3). The relationship between $\delta A m p_{e s}$ (eq. 8) and $\delta W_{0, e s l}^{S}$ (eq. 3) is described by eq. (9), and their standard deviations, $\phi_{S S}^{A m p}$ (Rodríguez-Marek et al. 2011) and $\phi_{s s}$ (Lin et al. 2011), are compared in Fig. 2. It shows that the two are comparable, based on which Stewart et al. (2017) concluded that $\phi_{s s}$ is dominated by the variability pertaining to site response, that is $\phi_{S S}^{A m p}$. Fig. 2 illustrates that both $\phi_{s s}$ and $\phi_{S S}^{A m p}$ are quite stable across the examined period band, ranging between 0.23 and 0.31 in In scales.

Also shown in Fig. 2 is the within-site variability of site response derived by Kaklamanos \& Bradley (2018) $\left(\sigma_{0}\right)$ and Stewart \& Afshari (2020) $\left(\phi_{\ln Y}^{G}\right)$ using surface-downhole pairs in Japan 

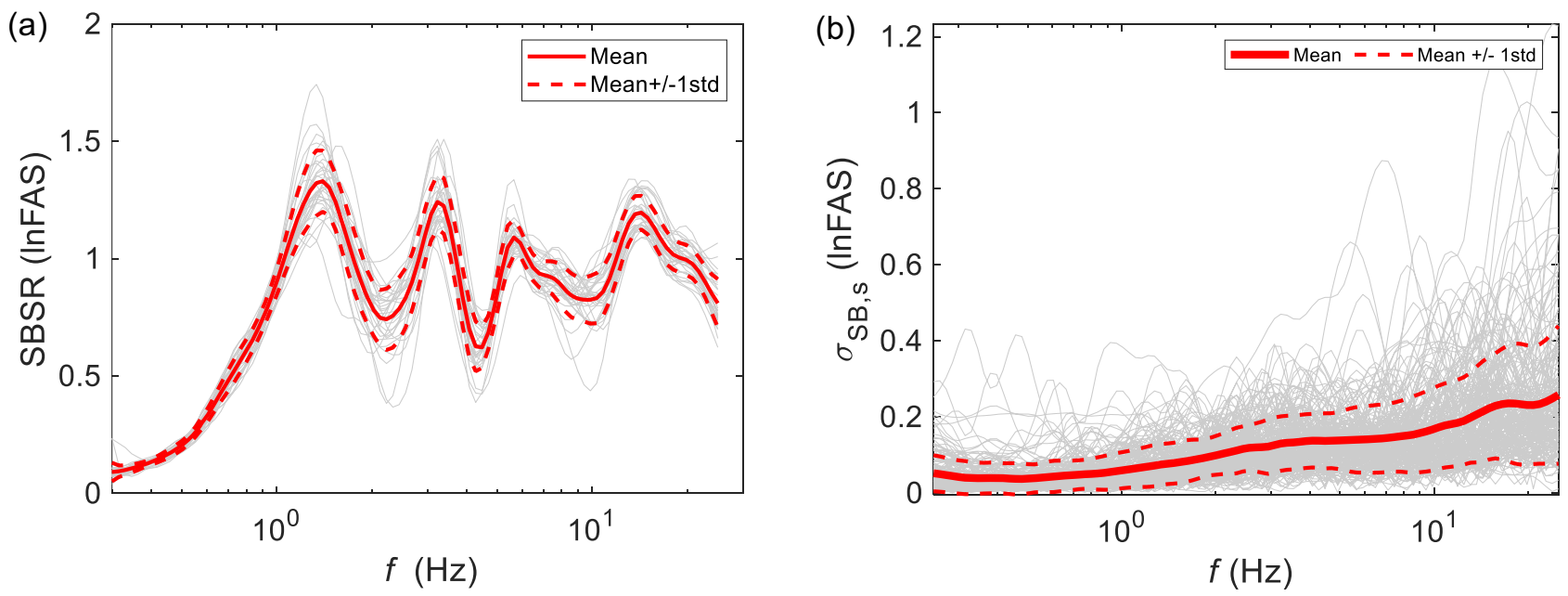

Figure 1. (a) $\mathrm{SBSR}_{\mathrm{es}} \mathrm{S}$ at the KiK-net site IWTH16 and their statistics: mean $\left(\mathrm{SBSR}_{s}\right)$ and one standard deviation (std) $\left(\sigma_{\mathrm{SB}, \mathrm{s}}\right)$ range where each grey line corresponds to one earthquake; (b) $\sigma_{\mathrm{SB}, \mathrm{s}} \mathrm{S}$ for $207 \mathrm{KiK}$-net sites selected by Zhu et al. (2019) where each grey line corresponds to one site with at least earthquake recordings. lnFAS means that $\mathrm{SBSR}_{\mathrm{es}}$ is computed based on FAS in $\ln$ scales.

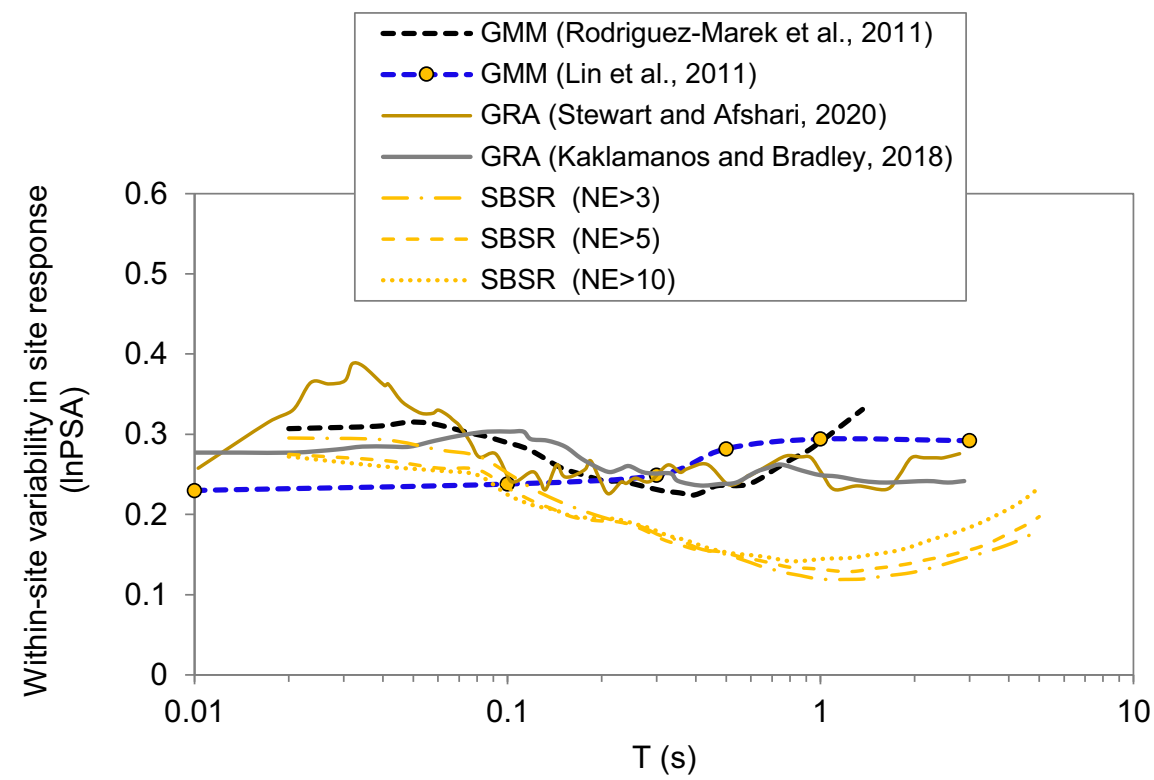

Figure 2. Within-site variability in site response separated via empirical ground-motion models (GMMs, $\phi_{S S}^{A m p}$ by Rodríguez-Marek et al. 2011 and the eventand path-corrected single-station standard deviation or single-path phi $\phi_{s s}$ by Lin et al. 2011), and those derived via 1-D ground response analyses (GRAs, $\sigma_{0}$ by Kaklamanos \& Bradley 2018 and $\phi_{\ln Y}^{G}$ by Stewart \& Afshari 2020), as well as those directly from SBSR at 207 KiK-net sites (Zhu et al. 2019). Unlike Fig. 1(b), SBSR results here are recomputed based on response spectrum (PSA) when different minimum numbers of earthquake recordings (NE) per site are utilized.

and California, respectively. In both studies, within-site variability is taken as the standard deviation of the residuals between observed site responses (SBSRs) and predictions from 1-D numerical simulations assuming vertical incidence of $\mathrm{SH}$ waves, that is GRAs. Results from GRAs, that is $\sigma_{0}$ and $\phi_{\ln Y}^{G}$, are comparable to those from GMMs which utilize generic site-response models based on site parameters. This is because the randomness in site response at individual sites is aleatory and cannot be reduced via the use of conventional site-response estimation approaches, for example ergodic site-response models and 1-D GRA (e.g. Ktenidou et al. 2018). In other words, site response aleatory variability is independent of conventional site-response estimation approaches. One potential way to reduce this variability is via 3-D physics-based modellings which include source, path and site effects simultaneously.
$\sigma_{\mathrm{SB}}(\operatorname{lnPSA})$ for the $207 \mathrm{KiK}-n$ et sites selected by Zhu et al. (2019) is also presented in Fig. 2. We varied the minimum number of recordings per site (NE) when deriving $\sigma_{\mathrm{SB}, \mathrm{s}}$. However, Fig. 2 shows that the mean value of $\sigma_{\mathrm{SB}, \mathrm{s}}$ across many sites, that is $\sigma_{\mathrm{SB}}$, is not very sensitive to NE. The same is also reported on the event-corrected single-station variability in empirical ground motion modellings (e.g. Lanzano et al. 2017). Besides, Fig. 2 indicates that $\sigma_{\mathrm{SB}}$ is comparable to $\sigma_{0}$ (Lin et al. 2011) and $\phi_{S S}^{A m p}$ (Rodríguez-Marek et al. 2011) from GMMs only for relatively low spectral periods but is lower than the latter at longer periods. This is because SBSR only represents the site response associated with the soil column between surface and downhole sensors but neglects the site response of the deeper structures and thus its variability. This can be more clearly demonstrated in the Fourier domain in Fig. 3 using 90 KiK-net sites. These 90 sites are further selected from the 207 sites (Fig. 1b) by 


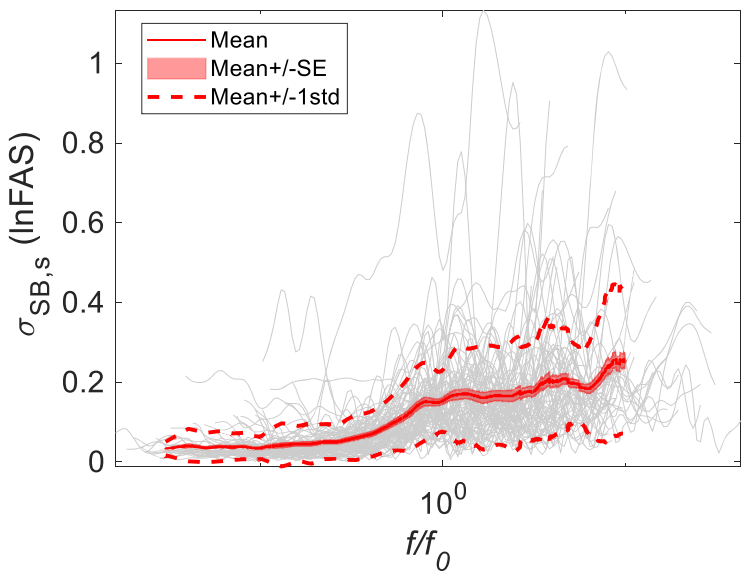

Figure 3. $\sigma_{\mathrm{SB}, \mathrm{s}}$ for $90 \mathrm{KiK}-\mathrm{net}$ stations selected by Zhu et al. (2020). The oscillator frequency is normalized to $f_{0}$ which is the site fundamental resonant frequency on SBSR. SE represents the standard error of the mean estimate, and std stands for the sample standard deviation.

Zhu et al. (2020) as having no significant velocity contrast below the borehole. Fig. 3 illustrates that $\sigma_{\mathrm{SB}}$ is nearly negligible for $f<f_{0}$. Therefore, $\sigma_{\mathrm{SB}}$ can only represent the aleatory variability of the site response at oscillator frequencies higher than the site fundamental frequency $\left(f>f_{0}\right)$ but significantly underestimates the variability for $f<f_{0}$.

\section{WITHIN-SITE VARIABILITY IN EARTHQUAKE HVSR}

Horizontal-to-vertical spectral ratio (HVSR) technique (Nakamura $1989,2019)$ is a cost-effective and thus widely utilized approach in site effect assessments as reviewed by Bard (1999). For a threecomponent surface recording, its HVSR is derived as the spectral ratio of the mean of the two horizontal components (NS and EW) to the vertical component. Similar to SBSR, the HVSR of an earthquake $e$ at a specific site $s$ can be expressed as:

$\ln \mathrm{HVSR}_{\mathrm{es}}=\ln \mathrm{HVSR}_{\mathrm{s}}+\varepsilon_{\mathrm{HV},{ }_{e s}} \sigma_{\mathrm{HV}, s}$,

where $\ln \mathrm{HVSR}_{\mathrm{s}}$ and $\sigma_{H V, s}$ (single-station HVSR sigma) are the mean and standard deviation, respectively, of ln $\mathrm{HVSR}_{\mathrm{es}}$ over many earthquakes at a given site $s$; $\varepsilon_{H V}$, es denotes the distance of ln HVSR $_{\text {es }}$ for a specific event from the mean in terms of number of standard deviations and is a standard normal random variable. The average of $\sigma_{H V, S}$ across many sites is denoted as $\sigma_{H V}$. By default, HVSR is obtained from the Fourier spectrum in ln scales, that is lnFAS.

To quantify $\sigma_{\mathrm{HV}, \mathrm{s}}$ for each KiK-net and K-NET site, we use a large strong-motion database which was used by Zhu et al. (2021) to derive $\mathrm{HVSR}_{\mathrm{s}}$ data for an open-source site database. There are 696242 seismograms (three components) recorded by K-NET and KiK-net surface stations from 15466 events between 1996 and 2019 (Fig. 4). Peak ground accelerations (PGAs) of these recordings are in the range between 0.001 and $0.1 \mathrm{~g}$, thus these data were not significantly affected by soil non-linearity. There is a relatively large number of records at each station (Fig. 4) in the database, and the mean HVSR curve at each site is published in the site database (Zhu et al. 2021). However, in this study on HVSR sigma, we focus on stations that recorded at least five events, which results in 697 KiK-net and $1169 \mathrm{~K}-\mathrm{NET}$ recording sites in the database.
$\sigma_{\mathrm{HV}, \mathrm{s}}$ for each of the $697 \mathrm{KiK}$-net and $1169 \mathrm{~K}-\mathrm{NET}$ sites is presented in Fig. 5. K-NET data is not used at low frequencies (< $\sim 1.0 \mathrm{~Hz}$ ) due to potential contamination of noises. $\sigma_{\mathrm{HV}}$ and its standard deviation (Fig. 5) are also provided as an electronic supplement (Table S1, Section 'Data and Resources'). For $f>\sim 1.0 \mathrm{~Hz}$, results from the two networks are consistent, and $\sigma_{\mathrm{HV}}$ is relatively stable across frequency, centring at $0.23-0.28$ (ln scales, a linear scale factor of $1.26-1.32$ ) with a 1 std $\sim 0.07$. This agrees with the results of a case study on EUROSEISTEST site (Maufroy et al. 2017). At frequencies lower than $\sim 1.0 \mathrm{~Hz}, \sigma_{\mathrm{HV}}$ increases with the decrease in frequency, and is centred at $0.28-0.43$ (a linear scale factor of $1.32-1.54$ ) with a $1 \mathrm{std} \sim 0.09$. The higher HVSR variability at lower frequencies, as we will demonstrate in a later section 'Earthquake Magnitude and Distance', is related to source parameters, for example earthquake magnitude and source-to-site distance. However, it might also be relevant to the topographic and subsurface heterogeneities since low-frequency components can sense the velocity variation in a larger region. Besides, a lower signal-to-noise ratio in the low-frequency range may also play a role. As will be discussed in the section 'Region Dependence', noise recordings tend to produce a more variable HVSR at low frequencies than earthquake motions.

Then we use the subset of $90 \mathrm{KiK}-$ net sites (Fig. 3) and compare its corresponding $\sigma_{\mathrm{SB}, \mathrm{s}}$ with $\sigma_{\mathrm{HV}, \mathrm{s}}$ in Fig. 6(a). In the usable frequency range of SBSR, that is $f>f_{0}$ as explained earlier, $\sigma_{\mathrm{HV}}$ is comparable to $\sigma_{\mathrm{SB}}$ in the aggregate, which suggests that the HVSR technique can be used to infer site response variability on average. Besides, Fig. 6(a) also suggests that the difference between $\sigma_{\mathrm{HV}, \mathrm{s}}$ and $\sigma_{\mathrm{SB}, \mathrm{s}}$ at individual sites does not have a significant scatter ( $\sim 0.1$ in $\ln$ scales), thus $\sigma_{\mathrm{HV}, \mathrm{s}}$ can be utilized to approximate site response variability at individual sites. In contrast, for $f<f_{0}$ in which SBSR is unusable, $\sigma_{\mathrm{SB}}$ is lower than $\sigma_{\mathrm{HV}}$. According to the diffuse field theory (Kawase et al. 2011), $\sigma_{\mathrm{HV}}$ may reflect the variability of site response associated with structures above the seismological bedrock beneath a target site and thus can better reflect the randomness of site response than $\sigma_{\mathrm{SB}}$ in the relatively low-frequency range.

Next, we compare $\sigma_{\mathrm{HV}, \mathrm{s}}$ with its corresponding $\sigma_{\mathrm{HVb}, \mathrm{s}}($ borehole) at the $90 \mathrm{KiK}$-net stations in Fig. 6(b). The two are approximately equal at frequencies lower than $\sim 10 \mathrm{~Hz}$, however, in the higher frequency range, $\sigma_{\mathrm{HV}}$ is slightly higher than $\sigma_{\mathrm{HVb}}$ by 0.03 (ln scales) on average. This may be attributable to that some sites in the data set experience temporal variation in soil properties within the topmost few meters, for example due to meteorological factors, including rainfall, freezing and thawing. Also, we cannot rule out the potential impact of soil non-linearity even though we only used ground motion with PGA of less than $0.1 \mathrm{~g}$. This is because various studies (e.g. Wang et al. 2021) show that sites that undergone non-linearity during strong shakings need as long as years for their near-surface deposits to 'bounce back'. These temporal changes in surficial soil properties affect the site response at high frequencies, as shown by Roumelioti et al. (2019). The impact is more apparent on component-wise $\sigma_{\mathrm{HV}}$ (Fig. 6b), but the difference is no more than 0.1 (ln scales).

KiK-net stations only have one sensor at depth. To depict a more detailed evolution of $\sigma_{\mathrm{HV}, \mathrm{s}}$ with depth, we use the Garner Valley Downhole Array (GVDA) in Southern California. GVDA consists of accelerometers at the ground surface (station code: 0 ) and five different depths (station code: $1-5$, Fig. 7a). We use the same recordings as selected in a preceding study by Zhu et al. (2020). At GVDA, $\sigma_{\mathrm{HV}, \mathrm{S}} \mathrm{S}$ do not vary significantly with depth (Fig. $7 \mathrm{~b}$ ) which agrees with the results from KiK-net sites (Fig. 6b). This may be explained 

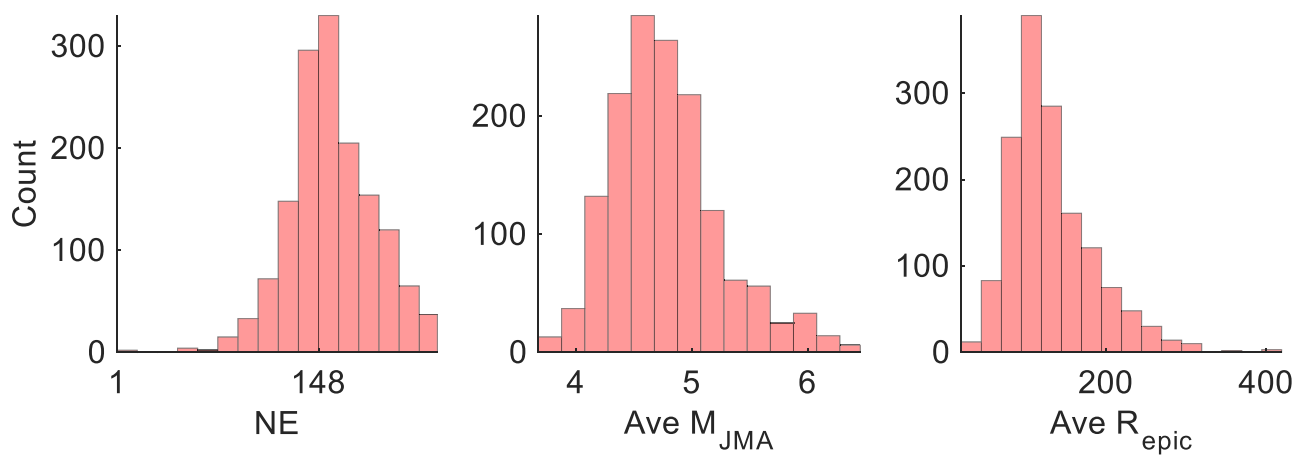

Figure 4. Histograms of the number of earthquakes per station (NE), average magnitude $\left(M_{\mathrm{JMA}}\right)$ and epicentral distance $\left(R_{\mathrm{epic}}\right)$ of these recordings at each KiK-net and K-NET station.

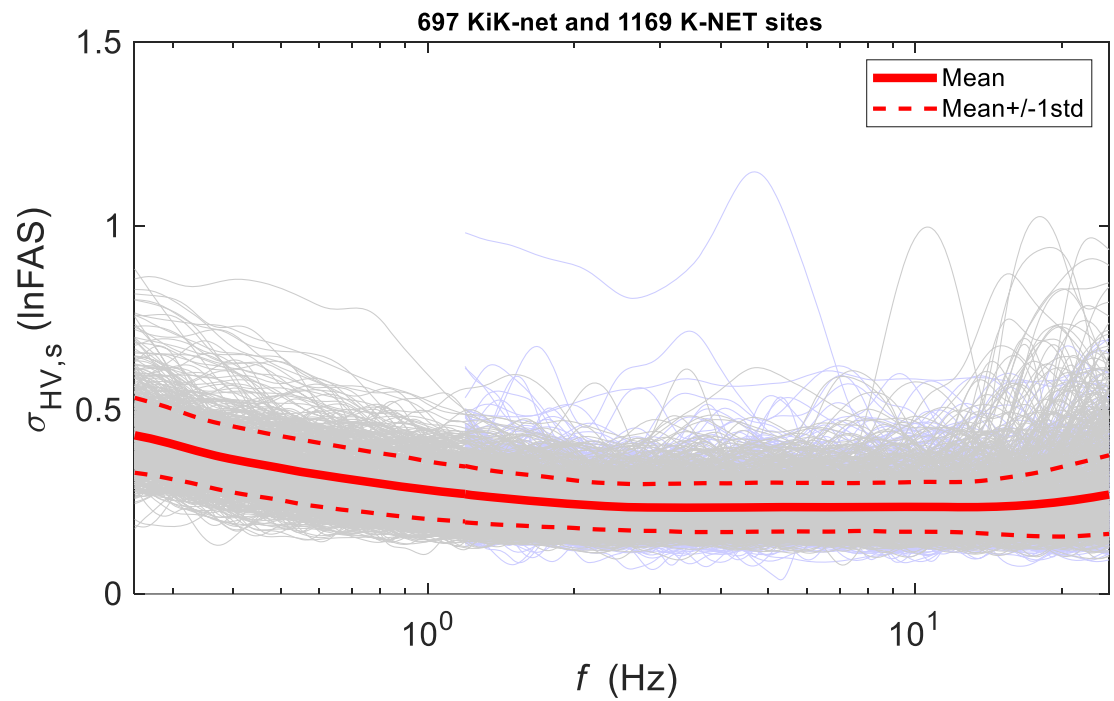

Figure 5. $\sigma_{\mathrm{HV}, \mathrm{s}}$ for $697 \mathrm{KiK}-$ net and $1169 \mathrm{~K}-\mathrm{NET}$ sites. There are at least five recordings (i.e. NE $\geq 5$ ) at each of these stations. K-NET recordings are only used for frequencies higher than $\sim 1.0 \mathrm{~Hz}$.
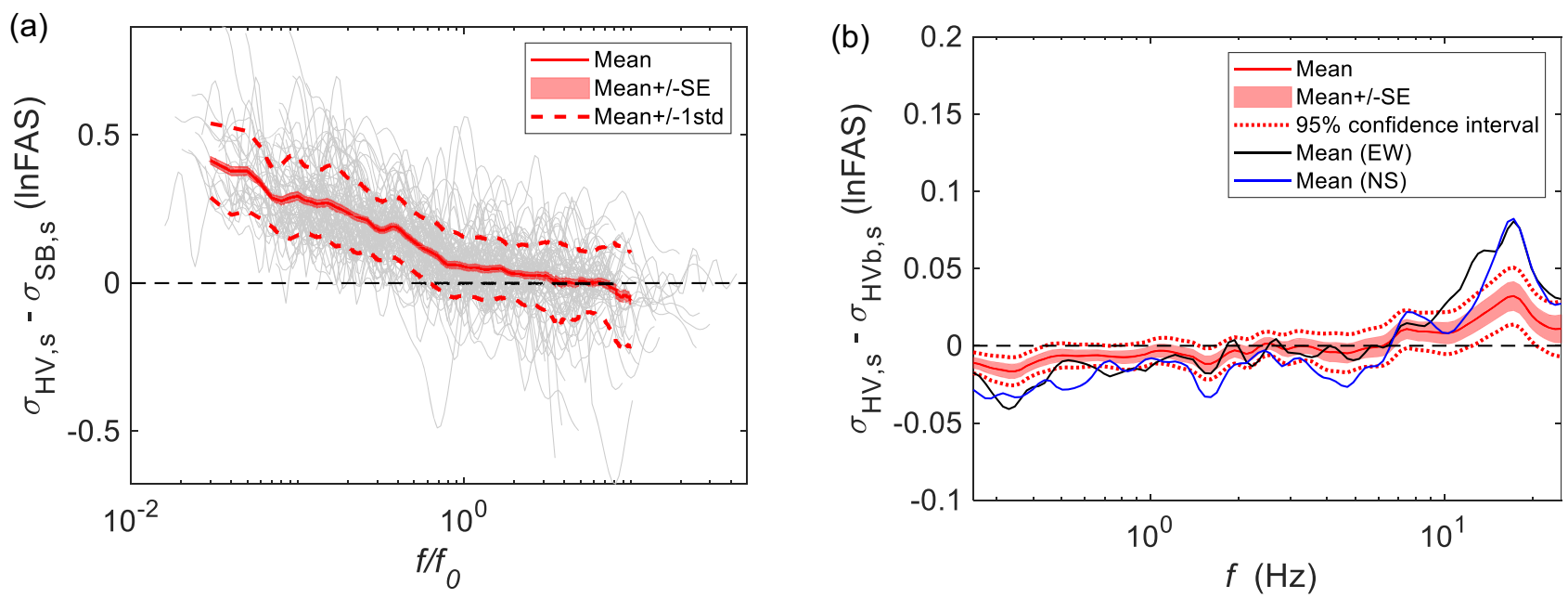

Figure 6. Statistics of the difference (a) between $\sigma_{\mathrm{HV}, \mathrm{s}}$ and $\sigma_{\mathrm{SB}, \mathrm{s}}$; and (b) between $\sigma_{\mathrm{HV}, \mathrm{s}}$ (surface) and $\sigma_{\mathrm{HVb}, \mathrm{s}}$ (borehole) at the $90 \mathrm{KiK}-$ net stations (lnFAS). $f_{0}$ is the site fundamental resonant frequency on SBSR. SE represents the standard error of the mean estimate, and std stands for the sample standard deviation.

by the fact that within-site amplification variability arises primarily due to the randomness in azimuth, incident angle, and complex incident wave field. Also displayed in Fig. 7(b) are results for $\sigma_{\mathrm{SB}, \mathrm{s}}$, which again confirms that SBSR underestimates the variability in site response (below its fundamental frequency) as observed at KiKnet sites (Fig. 3).

The mean value of $\sigma_{\mathrm{HV}, \mathrm{s}}$ across all K-NET and KiK-net sites (Fig. 5), namely $\sigma_{\mathrm{HV}}$, is shown in Fig. 8 together with the site 
(a)

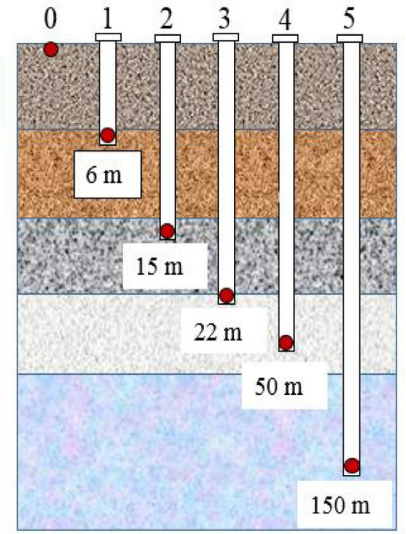

(b)

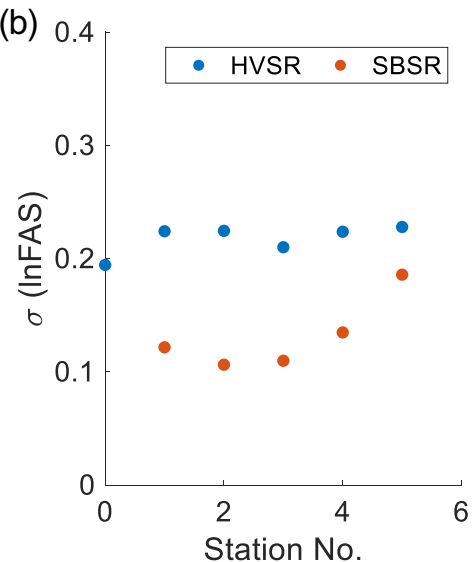

Figure 7. (a) Schematic diagram (not to scale) showing the depths of accelerometers (0-5) at the Garner Valley Downhole Array (GVDA) (after Zhu et al. 2020); and (b) $\sigma_{\mathrm{HV}, \mathrm{s}}$ for HVSR at accelerometers $0-5$ and $\sigma_{\mathrm{SB}, \mathrm{s}}$ of SBSR from the ground surface to various depths, both are averaged over the frequency range from 1.0 to $25 \mathrm{~Hz}$. Individual $\sigma_{\mathrm{HV}, \mathrm{s}}$ and $\sigma_{\mathrm{SB}, \mathrm{s}}$ curves are given shown in Fig. S1 (see Section 'Data and Resources').

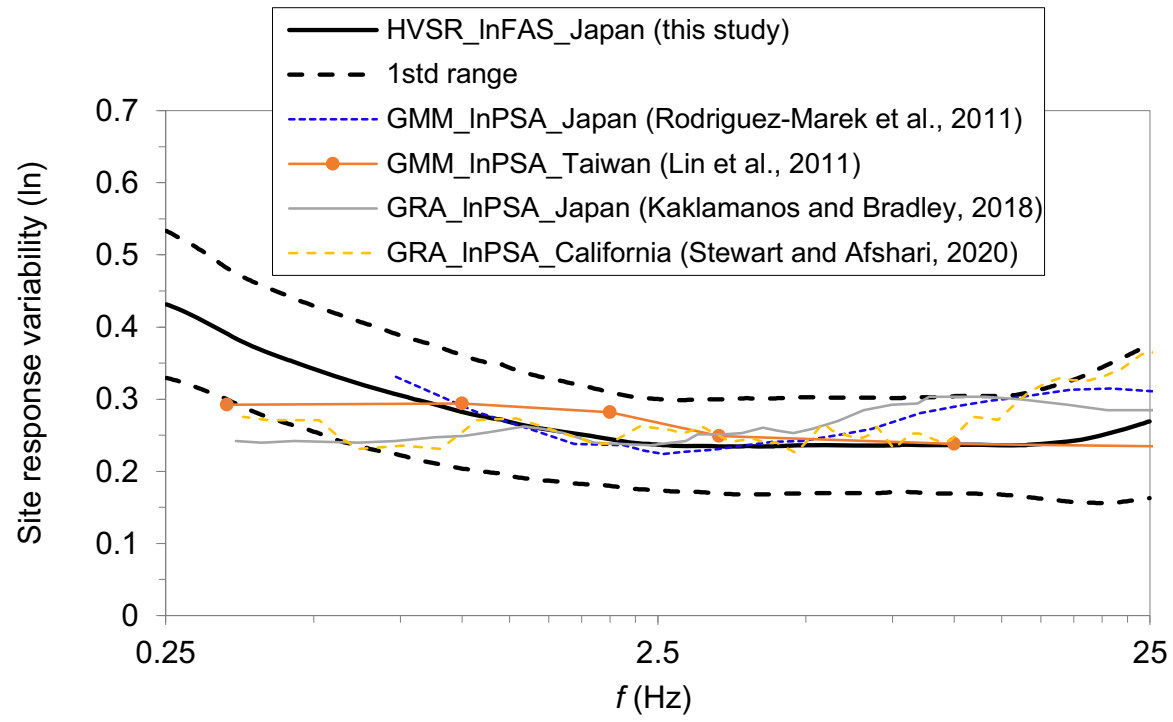

Figure 8. $\sigma_{\mathrm{HV}}$ (black solid line) for $697 \mathrm{KiK}$-net and $1169 \mathrm{~K}-\mathrm{NET}$ sites and its one standard deviation range (black dashed lines). Also superimposed are the intrasite variabilities in site response from various studies as displayed in Fig. 2 ( $\phi_{S S}^{A m p}$ by Rodríguez-Marek et al. 2011, single-path $\phi_{s s}$ by Lin et al. 2011, $\sigma_{0}$ by Kaklamanos \& Bradley 2018, and $\phi_{\ln Y}^{G}$ by Stewart \& Afshari 2020).

response variability from GMMs ( $\phi_{S S}^{A m p}$ by Rodríguez-Marek et al. 2011; event- and path-corrected single-station $\phi_{s s}$ by Lin et al. 2011) and GRAs $\left(\sigma_{0}\right.$ by Kaklamanos \& Bradley 2018; $\phi_{\ln Y}^{G}$ by Stewart $\&$ Afshari 2020). Though results of the previous studies are based on response spectrum (PSA) whereas ours are based on FAS, we compared the $\sigma_{\mathrm{HV}} \mathrm{S}$ from PSA- and FAS-based HVSRs and only found a relatively minor difference (Fig. S2, see Section 'Data and Resources').

In the frequency range from 1.0 to $25 \mathrm{~Hz}$ (Fig. 8), the level of randomness in site response from GMMs and GRAs agrees with the $\sigma_{\mathrm{HV}}$ from our study, falling within its one standard deviation range (centring at $0.23-0.28$ with a bandwidth of $\sim 0.07$ ). Results at low frequencies $(<1.0 \mathrm{~Hz})$ are not compared. This is because, at low frequencies, $\sigma_{\mathrm{HV}}$ shows dependence on source parameters, for example earthquake magnitude and source-to-site distance, as demonstrated in the section 'Earthquake Magnitude and Distance'. Thus, $\sigma_{\mathrm{HV}}$ at low frequencies is higher than the results from GMMs (Lin et al. 2011; Rodríguez-Marek et al. 2011) in which the site response variability at low frequencies is partially captured by the magnitude and distance metrics. For the results from GRA, Kaklamanos \& Bradley (2018) and Stewart \& Afshari (2020) utilized SBSR, and thus their results do not well capture this low-frequency variability (Fig. 3).

\section{DEPENDENCE OF HVSR SIGMAON SITE CONDITIONS AND EARTHQUAKE SCENARIOS}

\section{Site conditions}

In this section, we examine the dependence of $\sigma_{\mathrm{HV}, \mathrm{s}}$ on geological and geomorphological conditions. Site characterization parameters/proxies, including $30 \mathrm{~m}$ average shear-wave velocity $\left(V_{\mathrm{S} 30}\right)$, site resonant frequency $\left(f_{\mathrm{p}, \mathrm{HV}}\right)$, the depth to $2.5 \mathrm{~km} \mathrm{~s}^{-1}$ velocity horizon $\left(Z_{2.5}\right)$, topographic roughness, and geomorphological unit, are collected from an open-source site database for K-NET and KiK-net 
stations developed by Zhu et al. (2021). The correlations between $\sigma_{\mathrm{HV}, \mathrm{s}}$ and these site proxies vary with frequency and are only evident in the frequency range between $\sim 1.0$ and $\sim 4 \mathrm{~Hz}$ (Fig. S3, see Section 'Data and Resources'). For instance, at $f=1.3 \mathrm{~Hz}$ (Fig. 9), $\sigma_{\mathrm{HV}, \mathrm{s}}$ is positively correlated with $V_{\mathrm{S} 30}, f_{\mathrm{p}, \mathrm{HV}}$, and roughness with Pearson's $r=0.38,0.39$ and 0.38 , respectively. These suggest a low correlation ( $r=0.30-0.49)$ according to the recommended interpretation to $r$ by Schober et al. (2018). We note that there exist other different interpretations to $r$ (e.g. Campbell \& Bozorgnia 2019). However, at the same frequency (Fig. 9), $\sigma_{\mathrm{HV}, \mathrm{s}}$ exhibits a moderate $(r=0.50-0.69)$ negative correlation with the depth to the $2.5 \mathrm{~km} \mathrm{~s}^{-1}$ horizon $Z_{2.5}$ which is inferred from a 3-D regional velocity model.

Fig. 9 implies that stiffer, rougher and shallower sites tend to have a higher $\sigma_{\mathrm{HV}, \mathrm{s}}$. This is likely due to that shallow and stiff sites are more likely to be in mountainous regions with rough terrain and thus tend to have a relatively large $\sigma_{\mathrm{HV}, \mathrm{s}}$. When sites are binned by their geomorphological category (Fig. 10), those in 'mountain' have the highest $\sigma_{\mathrm{HV}, \mathrm{s}}$ whereas sites in 'alluvial fan' and 'lowland' have a relative low $\sigma_{\mathrm{HV}, \mathrm{s}}$. However, $\sigma_{\mathrm{HV}, \mathrm{s}}$ for each geomorphological unit does not vary significantly and falls in a rather narrow range: $0.2-0.27$. Hence, we confirm the dependence of $\sigma_{\mathrm{HV}, \mathrm{s}}$ on geological or geomorphological conditions, but their association is low to moderate.

\section{Earthquake magnitude and distance}

Earthquake magnitude and source-to-site distance affect the composition of incident wavefield (e.g. body and surface waves) which would influence $\sigma_{\mathrm{HV}, \mathrm{s}}$ at a given site. Using the $697 \mathrm{KiK}$-net and 1169 K-NET sites, we then examine the magnitude $\left(M_{\mathrm{JMA}}\right)$ and epicentral distance $\left(R_{\text {epic }}\right)$ dependence of $\sigma_{\mathrm{HV}, \mathrm{s}}$ at three oscillator frequencies (Fig. 11). $M_{\mathrm{JMA}}$ and $R_{\text {epic }}$ are represented by their mean values of all events recorded at a given site. At relatively low frequencies, for example 0.5 and $1.3 \mathrm{~Hz}, \sigma_{\mathrm{HV}, \mathrm{s}}$ tends to decrease with the increase in $M_{\mathrm{JMA}}$ and $R_{\text {epic }}$. However, for $M_{\mathrm{JMA}}>\sim 5.5$ and $R_{\text {epic }}$ $>200 \mathrm{~km}, \sigma_{\mathrm{HV}, \mathrm{s}}$ is nearly constant. In comparison, at high frequencies, for example $15 \mathrm{~Hz}$ (Fig. 11), $\sigma_{\mathrm{HV}, \mathrm{s}}$ shows little dependence on $M_{\mathrm{JMA}}$ and $R_{\text {epic }}$. This demonstrates that small local events tend to produce more variable HVSR at relatively low oscillator frequencies $(<\sim 4.0 \mathrm{~Hz})$. Meanwhile, Fig. 11 also suggests that the $M_{\mathrm{JMA}^{-}}$ and $\mathrm{R}_{\text {epic }}$-dependence of $\sigma_{\mathrm{HV}}$ are partially responsible for the higher $\sigma_{\mathrm{HV}}$ at lower frequencies observed in Fig. 5 .

Based on numerical simulations, Zhao et al. (2009), as well as Zhao \& Zhang (2010) also reported a large scatter in response spectral amplification ratios at relatively long periods, e.g. 2.5-4.0 s for events with a small magnitude and within a short distance, but they did not give a physical explanation. It is known that near-field ground motions tend to be more variable because of the space-time complexity of the earthquake rupture process (e.g. Vyas et al. 2016), and the strong directivity and rupture complexity would lead to highly variable site responses for sites in the near-field. In addition, at short distances, the radiation pattern of seismic waves and the relative contributions of compression $(P)$ and shear $(S)$ waves would show large azimuthal variations which may also contribute to the high site-response variability.

Since $\sigma_{\mathrm{HV}, \mathrm{s}}$ is dependent on earthquake magnitude and sourceto-site distance (Fig. 11), we thus re-derive the mean and standard deviation (sigma) of HVSR at each K-NET and KiK-net site using recordings in different magnitude and distance bins (Fig. 12). Recordings are grouped into four magnitude bins and four distance bins, 16 bins in total. K-NET recordings are not used at $f<\sim 1.0 \mathrm{~Hz}$.
The minimum number of recordings per site in each bin is set at five. In a certain bin in which there are at least five sites, binned $\sigma_{\mathrm{HV}, \mathrm{s}}$ is then averaged across sites to obtain the binned mean and standard deviation (Fig. 12). One bin, $M_{\mathrm{JMA}}=2-5$ and $R_{\text {epic }}>400$, does not meet the requirement on the minimum number of sites, and thus no result is obtained. These binned $\sigma_{\mathrm{HV}} \mathrm{S}$ can be considered as magnitude- and distance-dependent $\sigma_{\mathrm{HV}}$ models and are provided in Table S2 as supplemental materials (see 'Data and Resources'). $\sigma_{\mathrm{HV}} \mathrm{s}$ for different bins are compiled in Fig. S4.

\section{Source-site azimuth}

Prior studies reported the directional (NS and EW) dependence of HVSR and attributed it to the surface or subsurface heterogeneity (e.g. Uebayashi et al. 2012; Ktenidou et al. 2016; Matsushima et al. 2017). However, in this study, we look into the variability of single-station HVSR from different earthquake sources, namely the source-site azimuthal dependence. We illustrate this using one KiKnet site GNMH05. This site sits at the margin of the Kanto (Tokyo) basin and thus has prominent 3D features. GNMH05 is a deep soft site with $V_{\mathrm{S} 30}=393 \mathrm{~m} \mathrm{~s}^{-1}$ and $Z_{1.0}=174 \mathrm{~m}$. Superficial layers consist of sediments from the Late Pleistocene to Holocene. At this station, we only consider events with $M_{\mathrm{JMA}}$ between 4.0 and 5.0 and $R_{\text {epic }}$ between 100 and $200 \mathrm{~km}$ to minimize the impacts of magnitude and distance on HVSR sigma, as discussed in the preceding section 'Earthquake Magnitude and Distance'.

A total number of 188 earthquakes is selected at GNMH05. These earthquakes are then divided into three different source regions in each of which there are at least 20 earthquakes (Fig. 13a). The mean and standard deviations of HVSR are then derived for each region, as well as for all regions (Figs $13 \mathrm{~b}$ and c). Region 3 contributes the largest number of events, and thus its corresponding $\sigma_{\mathrm{HV}, \mathrm{s}}$ dominates that for all earthquakes. HVSR mean is rather stable, however, HVSR sigma exhibits a clear dependence on source-site azimuth. This is consistent with the findings on the EUROSEISTEST site (Maufroy et al. 2017) and confirms the azimuthal dependence of $\sigma_{\mathrm{HV}, \mathrm{s}}$ at a site with prominent 3-D features.

\section{Region dependence}

To investigate whether $\sigma_{\mathrm{HV}}$ varies across regions, besides K-NET and KiK-net data in Japan, we also use data from Europe, the Middle East and China. Using the same data screening criteria as applied to K-NET and KiK-net data (PGA $<0.1 \mathrm{~g}$ and number of recordings per station $\geq 5$ ), we selected data from the Pan-European Engineering Strong Motion (ESM) flatfile (Lanzano et al. 2019) and the National Strong Motion Observation Network System (NSMONS) of China. Following the same procedure, $\sigma_{\mathrm{HV}}$ was derived for PanEuropean countries and China in the Fourier domain (Fig. 14).

Though $\sigma_{\mathrm{HV}, \mathrm{s}}$ at individual sites exhibits some dependence on site conditions and earthquake scenarios (Figs 9-11), the average of $\sigma_{\mathrm{HV}, \mathrm{s}}$ over earthquakes and a representative sample of sites does not vary significantly across regions (Fig. 14). $\sigma_{\mathrm{HV}} \mathrm{s}$ for regions outside Japan are approximately within the one standard deviation range of $\sigma_{\mathrm{HV}}$ for Japan. Considering the finding of Rodríguez-Marek et al. (2013) that the event-corrected single-station standard deviation (including the contribution from both path and site effects) to be remarkably stable across tectonic regions, Fig. 14 implies that the single-station variability associated with either wave-propagation path or site response, on average, has no significant region dependence. 


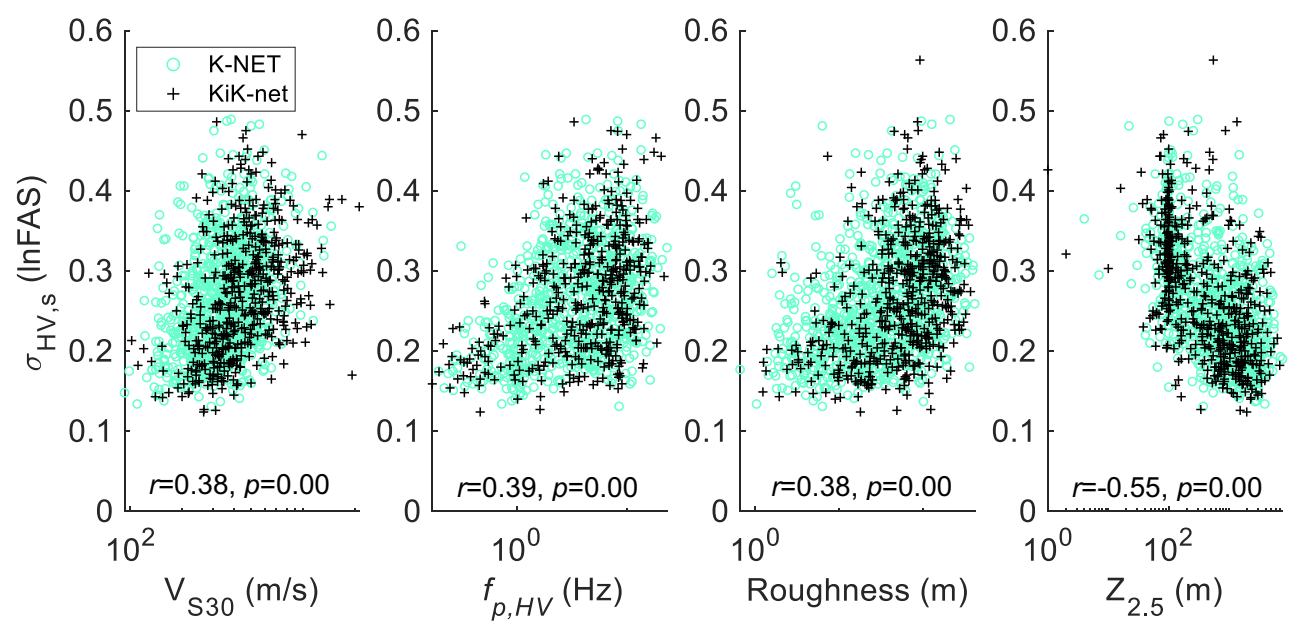

Figure 9. $\sigma_{\mathrm{HV}, \mathrm{s}}$ at $f=1.3 \mathrm{~Hz}$ versus $V_{\mathrm{S} 30}, f_{\mathrm{p}, \mathrm{HV}}$, surface roughness and $Z_{2.5}$, respectively at K-NET and KiK-net sites. $r$ is the Pearson's correlation coefficient with a $p$-value for the null hypothesis test at a significance level of 0.05 .

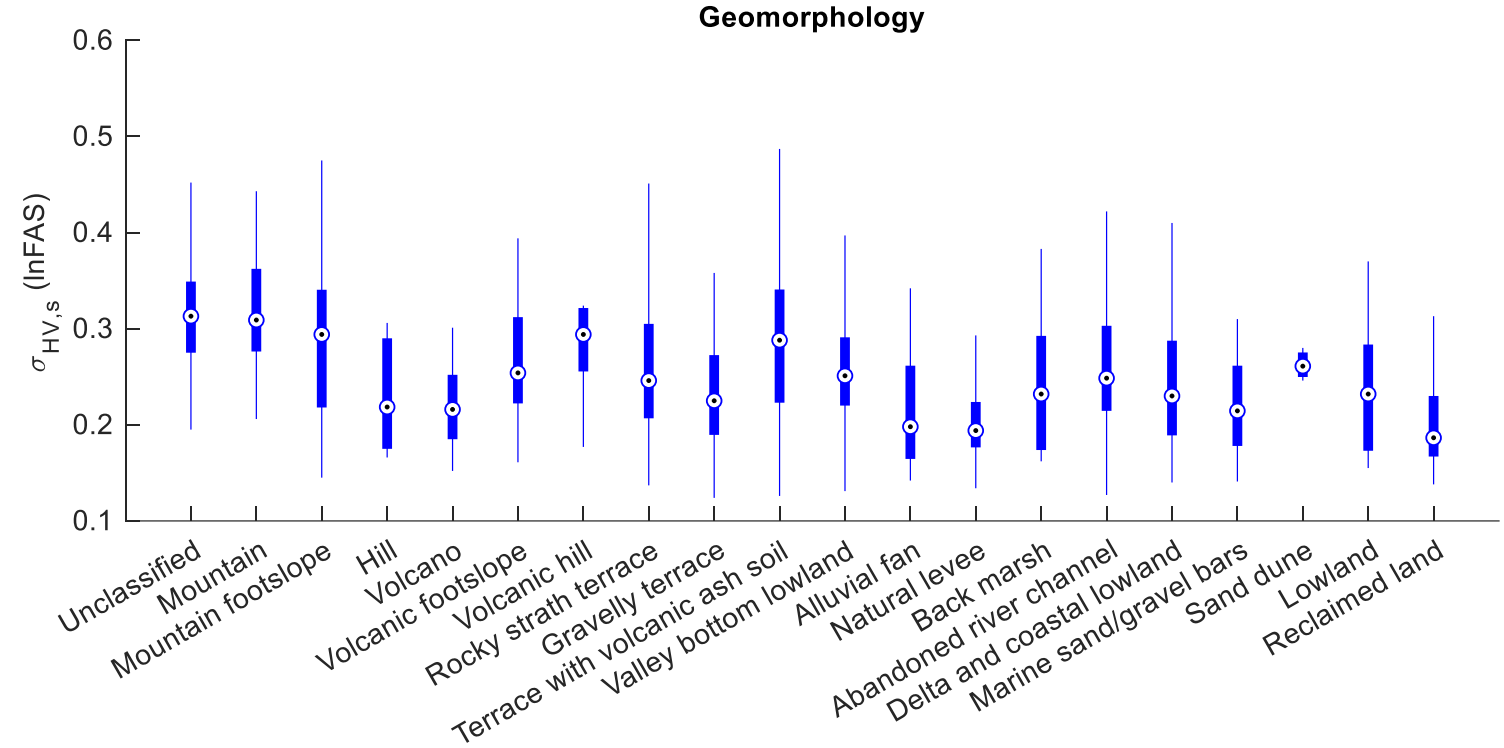

Figure 10. $\sigma_{\mathrm{HV}, \mathrm{s}}$ at $f=1.3 \mathrm{~Hz}$ for sites in each geomorphological category. On each box, the dot indicates the median, and the bottom and top edges of the bar indicate the 25th and 75th percentiles, respectively. The whiskers extend to the most extreme data points not considered outliers.

HVSR sigma of microtremors collected in urban areas of Santiago de Chile by Pilz et al. (2009) is also displayed in Fig. 14. Individual HVSR curves are depicted in Fig. S5 (see Section 'Data and Resources'). Fig. 14 shows that the HVSR sigma of microtremors is out of the one standard deviation range of earthquake HVSR sigma. A more thorough comparison of the two is beyond the scope of this study, and Fig. 14 suggests that the HVSR of microtremors may give different variabilities from that of earthquakes.

\section{DISCUSSION}

\section{Where would 1-D GRA likely to fail?}

$\sigma_{\mathrm{HV}, \mathrm{s}}$ is shown to have an association with site conditions (Figs 9 and 10). Sites with rougher terrains tend to have higher $\sigma_{\mathrm{HV}, \mathrm{s}}$, implying that $\sigma_{\mathrm{HV}, \mathrm{s}}$ carries some information on the irregularities of surface and subsurface topography, namely non-1-D features. Thus it is reasonable to assume that 1-D GRA tends to perform less well at sites with higher $\sigma_{\mathrm{HV}, \mathrm{s}}$. To test this assumption, we collect results of Pearson's $r$ between theoretical borehole response (theoretical transfer function $\mathrm{TTF}_{\text {in }}$ ) from 1-D GRA and observed borehole response from SBSR at a relatively large number of KiK-net sites from two independent studies by Kaklamanos \& Bradley (2018) and Zhu et al. (2020), respectively.

Kaklamanos \& Bradley (2018) selected $114 \mathrm{KiK}-$ net sites and computed Pearson's $r$ in the frequency range from $f_{0, \mathrm{TTF}}$ to the maximum between $4 f_{0, \mathrm{TTF}}$ and $20 \mathrm{~Hz}$ where $f_{0, \mathrm{TTF}}$ is the first peak frequency on $\mathrm{TTF}_{\text {in }}$. In contrast, Zhu et al. (2020) utilized $90 \mathrm{KiK}$ net sites and derived $r$ in the frequency range from $f_{0, \mathrm{TTF}}$ and $25 \mathrm{~Hz}$. Despite these differences, we plot the $r$ value of each site against its corresponding $\sigma_{\mathrm{HV}, \mathrm{s}}$ (averaged over $0.25-25 \mathrm{~Hz}$ ) derived in this study (Fig. 15). Both studies show a consistent decreasing trend in $r$ with the increase in $\sigma_{\mathrm{HV}, \mathrm{s}}$ which confirms that 1-D GRA tends to perform worse at sites with higher $\sigma_{\mathrm{HV}, \mathrm{s}}$. Thus $\sigma_{\mathrm{HV}, \mathrm{s}}$, to some extent, reflects the level of modelling uncertainty in GRA predictions, arising due to the violation of 1-D SH assumptions. We note that the trend in Fig. 15 is not very strong, which may be partially because $r$ is affected not only by modelling uncertainty but also by parametric 

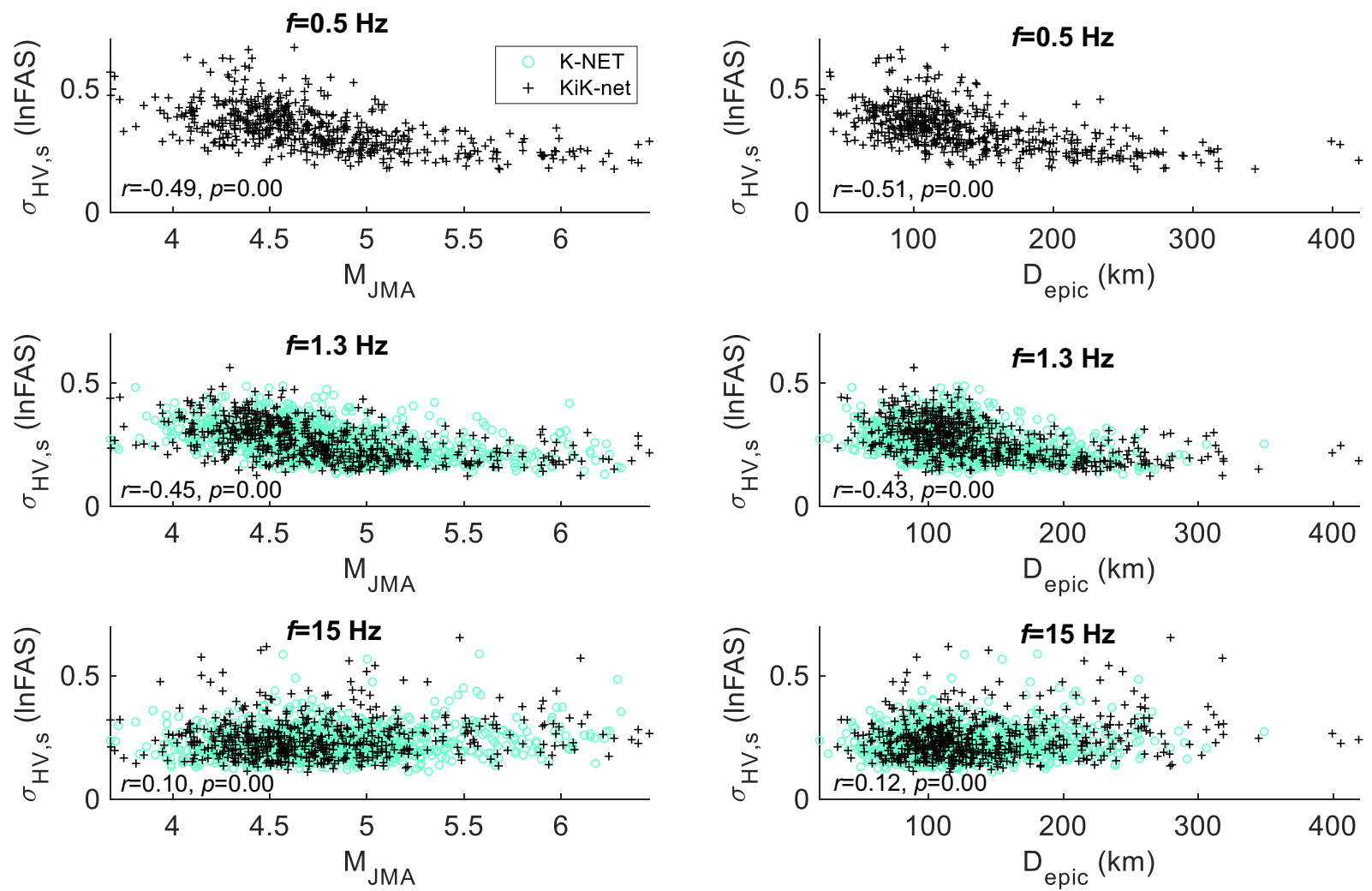

Figure 11. $\sigma_{\mathrm{HV}, \mathrm{s}}$ at $0.5 \mathrm{~Hz}$ (first row), $1.3 \mathrm{~Hz}$ (second row) and $15.0 \mathrm{~Hz}$ (third row) versus the mean magnitude $M_{\mathrm{JMA}}$ (left-hand column) and mean epicentral distance $R_{\text {epic }}$ (right-hand column) of earthquake recordings used to derived $\sigma_{\mathrm{HV}, \mathrm{s}}$ for at each of the 697 KiK-net and 1169 K-NET sites. $r$ is the Pearson's correlation coefficient with a $p$-value for the null hypothesis test at a significance level of 0.05 .
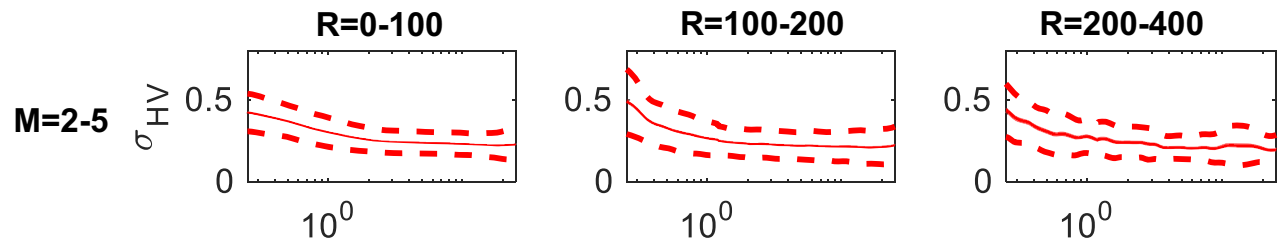

$\mathbf{R}>400$
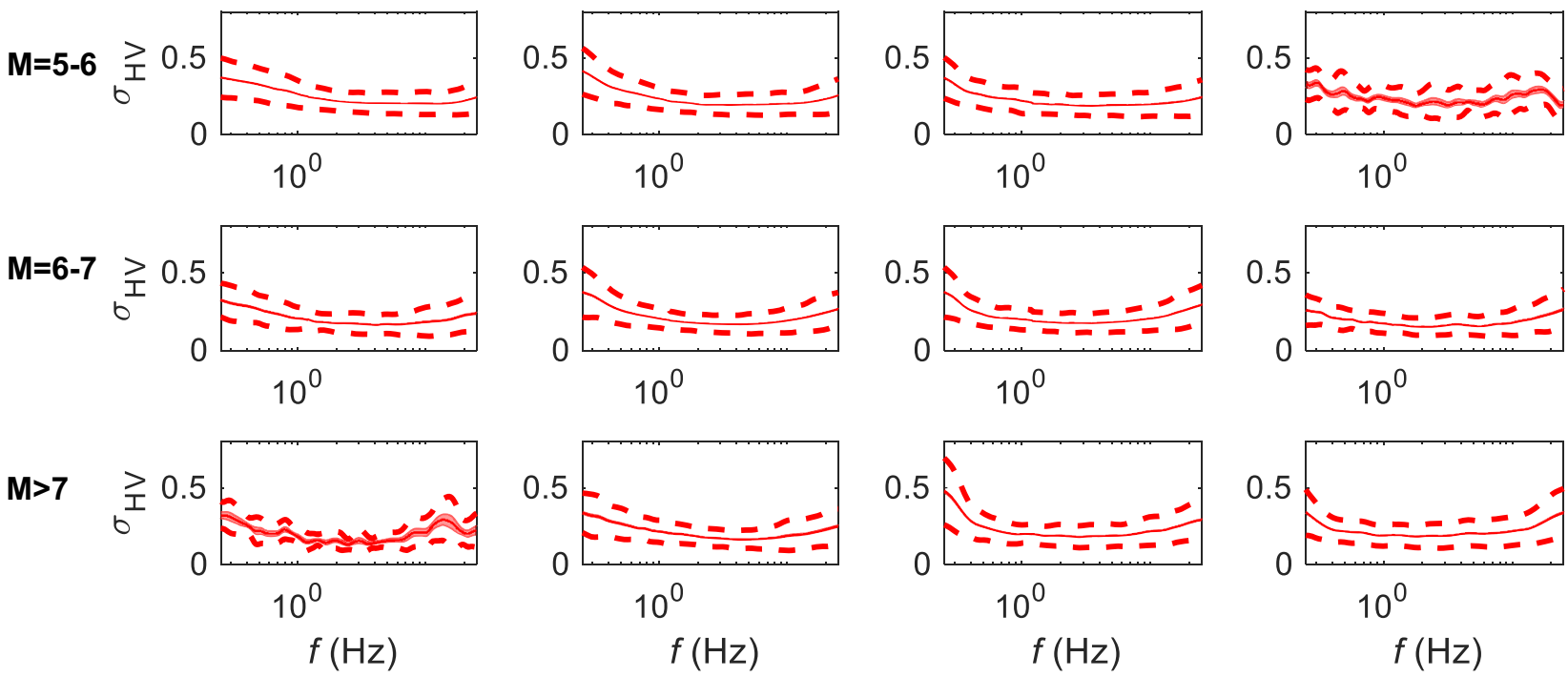

Figure 12. $\sigma_{\mathrm{HV}}(\operatorname{lnFAS})$ (solid line) from 0.25 to $25 \mathrm{~Hz}$ for 16 magnitude $\left(M_{\mathrm{JMA}}\right)$ - and epicentral distance $\left(R_{\text {epic }}\right)$-bins using $697 \mathrm{KiK}$-net and $1169 \mathrm{~K}-\mathrm{NET}$ sites. The dashed lines in each plot correspond to the mean $\pm 1 \mathrm{std}$, and the shaded zone represents the epistemic uncertainty of the mean estimate (mean \pm SE). 

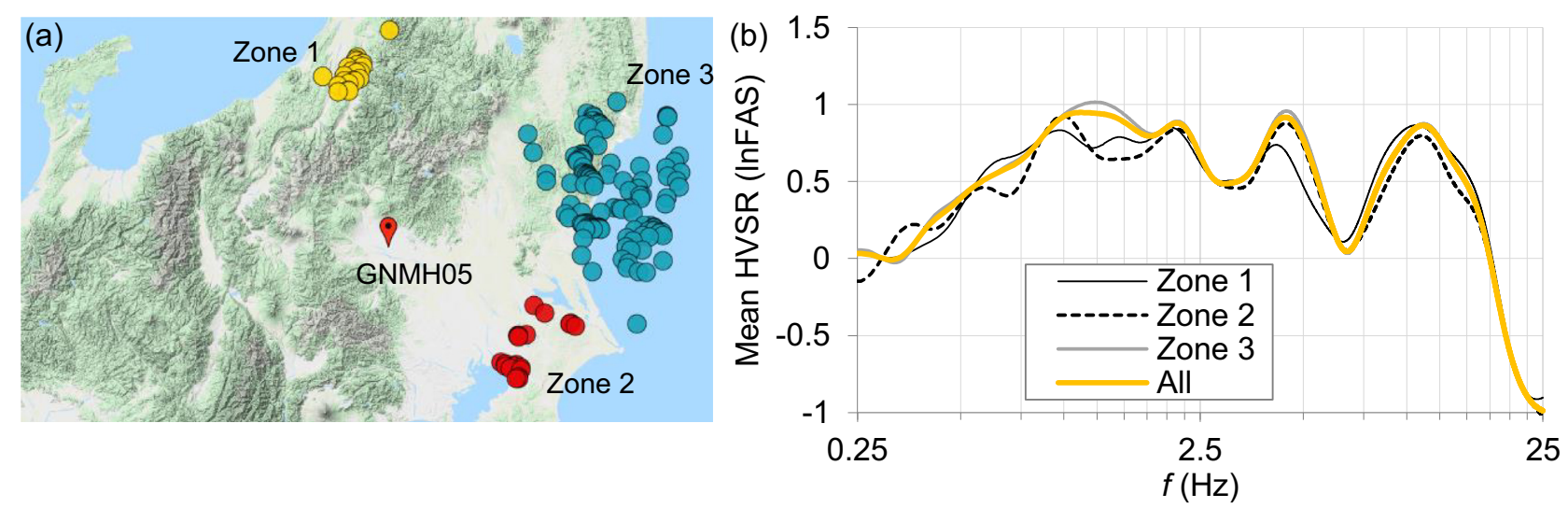

(c)

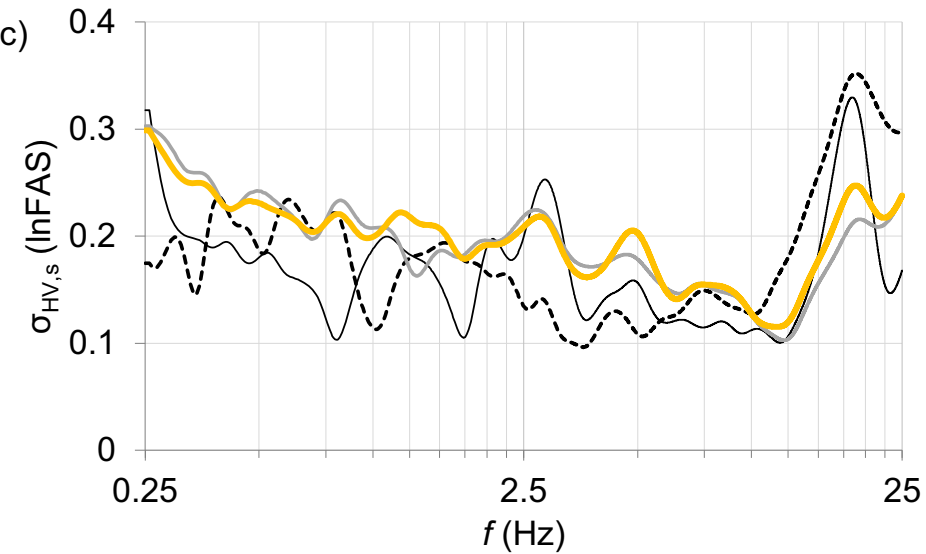

Figure 13. (a) Source distribution of 188 earthquakes recorded at KiK-net site GNMH05 with $\mathrm{M}_{\mathrm{JMA}}$ between 4.0 and 5.0 and epicentral distance between 100 and $200 \mathrm{~km}$; and (b) mean and (c) standard deviation of HVSR using earthquakes in different source regions. There are at least 20 earthquakes in each source region.

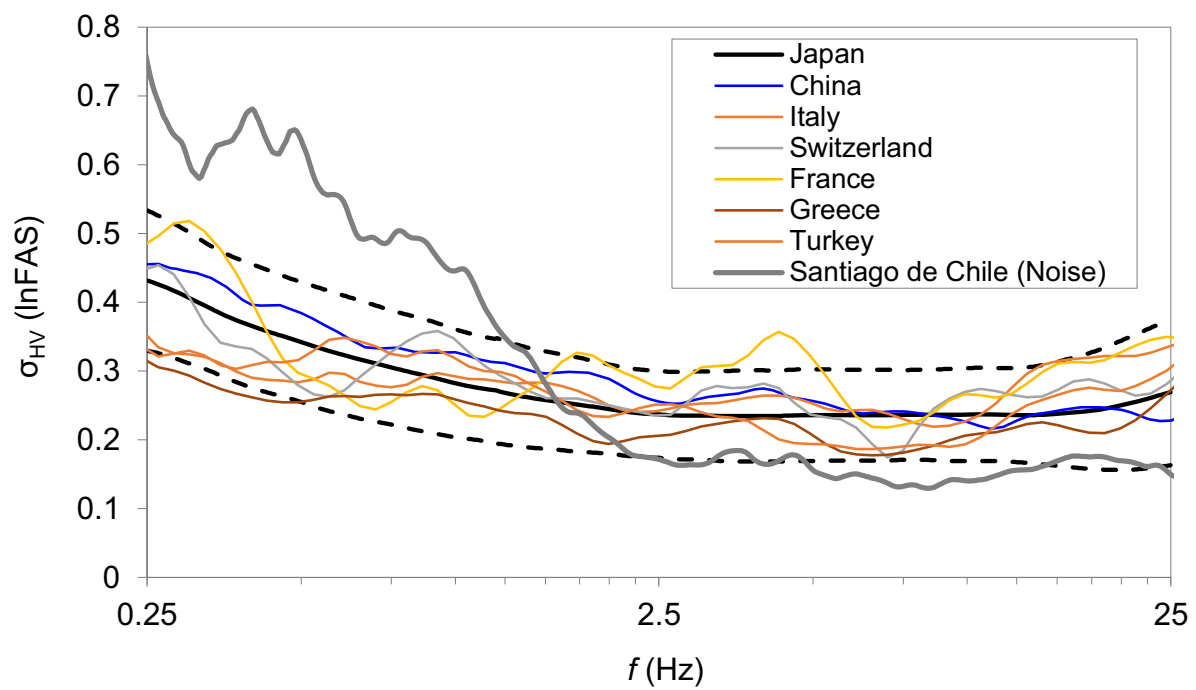

Figure 14. $\sigma_{\mathrm{HV}} \mathrm{S}(\operatorname{lnFAS})$ for different regions. The dashed lines correspond to the mean \pm 1 std range of $\sigma_{\mathrm{HV}}$ for Japan as shown in Fig. 5. The bold grey line corresponds to the $\sigma_{\mathrm{HV}}$ of noise (microtremor) recordings collected in the large urban area of Santiago de Chile by Pilz et al. (2009).

uncertainty. But $\sigma_{\mathrm{HV}, \mathrm{s}}$ contains no direct information on the latter, though we acknowledge that sites with a high $\sigma_{\mathrm{HV}, \mathrm{s}}$ are also likely to have a high parametric uncertainty.

Since Pearson's $r$ in Fig. 15 is also affected by the parametric uncertainty in the 1-D ground models used in GRA, we divide sites into two groups according to whether abs. $\left[\ln \left(f_{0, \mathrm{HV}} / f_{0, \mathrm{TTF}}\right)\right]$ is smaller than $\ln (1.25)$ or not. 'abs.' represents the absolute value of a number. $f_{0, \mathrm{HV}}$ is the first peak frequency on an HVSR curve and is collected from the site database (Zhu et al. 2021). The absolute value of $\ln \left(f_{0, \mathrm{HV}} / f_{0, \mathrm{TTF}}\right)$ reveals to what extent the ground model used in GRA can reproduce the observed fundamental resonant frequency from HVSR. Since 2-D 


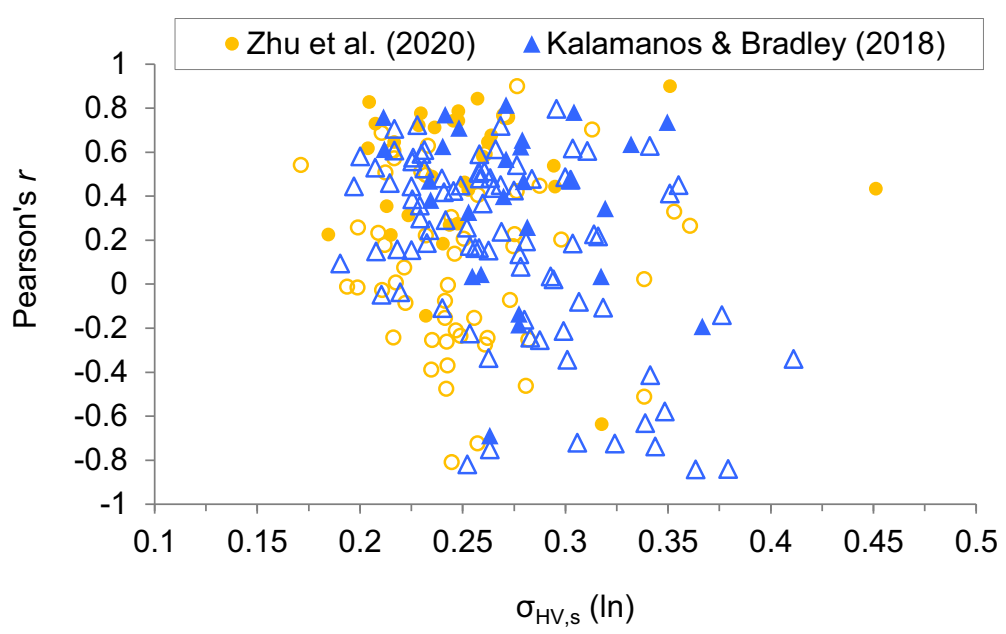

Figure 15. Relationship between the performance of 1-D ground response analysis (GRA) and $\sigma_{\mathrm{HV}, \mathrm{s}}$ averaged over $0.25-25 \mathrm{~Hz}$ at KiK-net sites. Pearson's $r$ was derived by Zhu et al. (2020) and Kalamanos \& Bradley (2018) between the theoretical transfer function (TTF in) from GRA under within boundary conditions and observed site response from SBSR. Filled symbols represent sites with abs. $\left[\ln \left(f_{0, \mathrm{HV}} / f_{0, \mathrm{TTF}}\right)\right]<\ln (1.25)$, and hollow symbols represent sites with abs. $\left[\ln \left(f_{0, \mathrm{HV}} / f_{0, \mathrm{TTF}}\right)\right] \geq \ln (1.25)$.

or 3-D effects do not have a significant impact on the fundamental resonant frequency, thus $\ln \left(f_{0, \mathrm{HV}} / f_{0, \mathrm{TTF}}\right)$, to a certain degree, reflects the level of parametric uncertainty in GRA results.

Sites with abs. $\left[\ln \left(f_{0, \mathrm{HV}} / f_{0, \mathrm{TTF}}\right)\right]<\ln (1.25)$ tends to have a higher $r$ value (Fig. 15). The average $r$ values at sites with abs. $\left[\ln \left(f_{0, \mathrm{HV}} / f_{0, \mathrm{TTF}}\right)\right]<\ln (1.25)$ or not are 0.49 and 0.15 , respectively, based on results from Zhu et al. (2021) whereas they are 0.38 and 0.18 for Kaklamanos \& Bradley (2018). This suggests that GRA is likely to perform well at these sites with abs. $\left[\ln \left(f_{0, \mathrm{HV}} / f_{0, \mathrm{TTF}}\right)\right]$ $<\ln (1.25)$. The above results justify further investigations on the potential application of the single-station HVSR technique, namely using two parameters from HVSR, that is $\sigma_{\mathrm{HV}, \mathrm{s}}$ and $f_{0, \mathrm{HV}}$, to evaluate the modelling and parametric uncertainties, respectively, in GRA results in forward applications.

\section{Site-specific or site- and event-specific amplification prediction?}

Fig. 16 depicts the between-site uncertainty and within-site variability in site response at sites in Japan. Between-site uncertainty is the standard deviation of site response residuals over selected sites between observations (over many events at individual sites) and mean predictions from GMM-native site-response models based on site characterization parameter(s). Exceptions is the result from Kotha et al. (2018) whose GMM is without a site response model, and thus their corresponding between-site uncertainty is the standard deviation of full site response. Since the inclusion of site response model into GMM can reduce the between-site uncertainty to a certain extent, thus the result from Kotha et al. (2018) serves as the upper bound of between-site uncertainty.

For $f<\sim 1.0 \mathrm{~Hz}$, the within-site variability quantified using HVSR shows dependence on magnitude and distance (Fig. 11). Thus, in a GMM framework, this within-site variability would be partially captured by the magnitude and distance metrics and could be lower than the $\sigma_{\text {HV }}$ shown in Fig. 16.

However, for $f>\sim 1.0 \mathrm{~Hz}$, the between-site uncertainties of various ergodic site response models are, in general, much higher than the within-site variability in site response (Fig. 11). The betweensite uncertainty varies with $f$ but is roughly in the range between 0.3 and 0.6 (a linear scale factor between 1.3 and 1.8) whereas the within-site variability in site response is centred around $0.23-0.28$ in $\ln$ scales (a linear scale factor of 1.26-1.32, Fig. 16). Considering that the total uncertainty of ground-motion predictions from PSA-based GMMs is typically in the range of 0.6-0.8 (a linear scale factor of 1.8-2.0, e.g. Douglas \& Edwards 2016), the between-site uncertainty has a more significant contribution than the within-site variability in site response. Zhu et al. (2021b) recently showed that predictions from 1-D GRA, which is often regarded as a site-specific approach, do not necessarily have a lower between-site uncertainty than ergodic models (Fig. 16). Therefore, future efforts are particularly needed to improve our ability in estimating the mean site response (over many events) at individual sites, that is site-specific amplification prediction.

\section{CONCLUSIONS}

In probabilistic seismic hazard/risk analyses, both the betweenand within-site variabilities in site response contribute to total uncertainty/variability in ground motions. In this study, we investigate the randomness (or aleatory variability) in linear site response at individual K-NET and KiK-net sites. We find that the singlestation HVSR sigma (standard deviation of horizontal-to-vertical spectral ratio from earthquake records) approximates the withinsite variability in site response quantified using co-located surfacedownhole pairs (SBSR for oscillator frequencies larger than the site fundamental frequency $f_{0}$ ) and empirical GMMs. Among them, SBSR underestimates the within-site variability for $f<f_{0}$. Empirical evidence shows that HVSR can serve as a convenient tool to assess the single-station variability in site response.

Results also show that the HVSR sigma at individual sites, that is $\sigma_{\mathrm{HV}, \mathrm{s}}$, has a low to moderate $(r=0.30-0.69)$ correlation with site-condition proxies (shear wave velocity, site resonant frequency, sediment thickness and surface roughness) at frequencies between $\sim 1.0$ and $\sim 5 \mathrm{~Hz}$. In this frequency range, stiffer, rougher and shallower sites tend to have a higher $\sigma_{\mathrm{HV}, \mathrm{s}}$. Also, $\sigma_{\mathrm{HV}, \mathrm{s}}$ shows a low to moderate $(r=0.30-0.69)$ dependence on earthquake magnitude and 


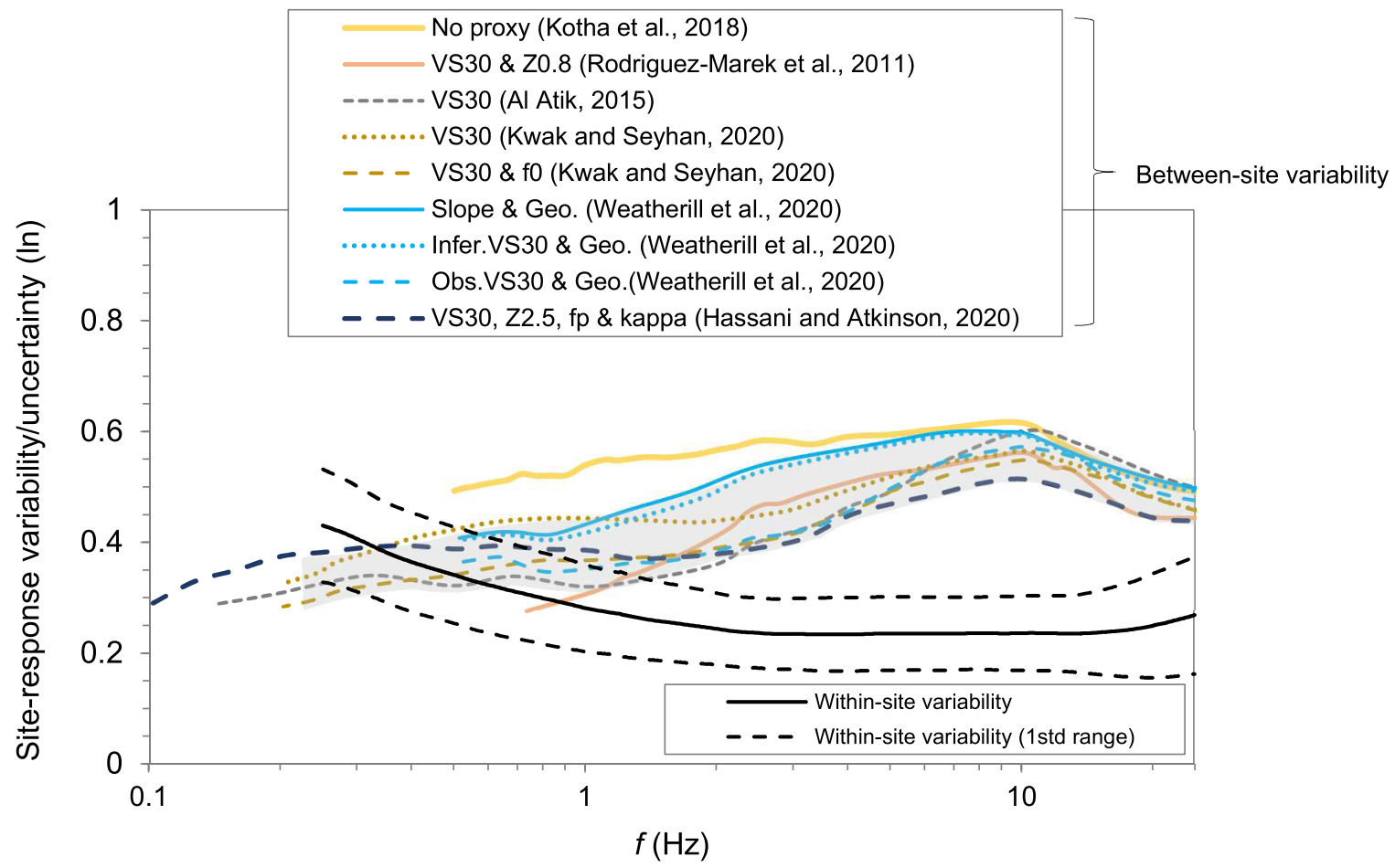

Figure 16. Between-site uncertainty (lnPSA) and within-site variability (lnFAS) in site response for sites in Japan. Between-site uncertainty is compiled from existing studies (Kotha et al., 2018; Rodriguez-Marek et al., 2011; Al Atik, 2015; Kwak and Seyhan, 2020; Weatherill et al., 2020; Hassani and Atkinson, 2020). Within-site variability is derived from HVSR data in this research (Fig. 5).

source-to-site distance at relatively low frequencies $(<\sim 4.0 \mathrm{~Hz})$ at which small and local events tend to produce more variable HVSR. In addition, $\sigma_{\mathrm{HV}, \mathrm{s}}$ exhibits a dependence on source-site azimuth.

However, the average single-station HVSR sigma over different events and sites, that is $\sigma_{\mathrm{HV}}$, has little fluctuation with frequency for $f>\sim 1.0 \mathrm{~Hz}$ and is centred at $0.23-0.28$ (In scales, a linear scale factor of 1.26-1.32) with one standard deviation of $\sim 0.07$. At frequencies lower than $\sim 1.0 \mathrm{~Hz}, \sigma_{\mathrm{HV}}$ increases gradually with decreasing frequency and is centred at $0.28-0.43$ (a linear scale factor of 1.32-1.54) with one standard deviation of $\sim 0.09$. Besides, $\sigma_{\mathrm{HV}}$ is quite stable across different tectonic regions.

Based on data, we present a constant, as well as magnitudeand distance-dependent HVSR sigma models. These sigma models reflect the inherent randomness in site response and indicate the uncertainty in predicting event-specific amplifications at individual sites using conventional approaches, for example proxy-based generic amplification models and 1-D GRA. However, future efforts are particularly needed to improve our ability in site-specific amplification prediction to reduce the between-site uncertainty which is much higher than the within-site variability in site response.

\section{DATA AND RESOURCES}

Strong-motion seismograms at K-NET and KiK-net stations were downloaded from http://www.kyoshin.bosai.go.jp/(last accessed on October 2020). Site data at K-NET and KiK-net stations are collected from an open-source site database via https://doi.org/10.588 0/GFZ.2.1.2020.006. Engineering Strong Motion Database (ESM) flatfile is available on https://doi.org/10.13127/esm/flatfile.1.0 on March 2021. Chinese strong-motion data was obtained from China
Strong Motion Network Centre (CSMNC) at the Institute of Engineering Mechanics, China Earthquake Administration (Apply for data by sending query e-mail to 'datashare@seis.ac.cn' and 'csmnc@iem.ac.cn'). Supplemental materials include two tables and five figures. Table S1 contains the means and standard deviations of $\sigma_{\mathrm{HV}}$, s at $697 \mathrm{KiK}$-net and $1169 \mathrm{~K}-\mathrm{NET}$ sites, as displayed in Fig. 6. Table S2 includes the magnitude- and distance-binned means and standard deviations of $\sigma_{\mathrm{HV}} \mathrm{s}$, as illustrated in Fig. 14. Fig. S1 depicts individual $\sigma_{\mathrm{HV}, \mathrm{s}}$ and $\sigma_{\mathrm{SB}, \mathrm{s}}$ curves for each sensor at the Garner Valley Downhole Array (GVDA). Fig. S2 illustrates the difference between $\sigma_{\mathrm{HV}}$ using PSA- and FAS-based HVSR. Fig. S3 shows the Pearson's correlations between site parameters $\left(V_{\mathrm{S} 30}, f_{\mathrm{P}, \mathrm{HV}}\right.$, Roughness and $Z_{2.5}$ in ln scales) and $\sigma_{\mathrm{HV}, \mathrm{s}}$ at different oscillator frequencies. Fig. S4 compiles $\sigma_{\mathrm{HV}}$ for each magnitude and distance bin. Fig. S5 displays $\sigma_{\mathrm{HV}, \mathrm{s}}$ of microtremors at sites in Santiago de Chile. HVSR sigma at individual sites will be published in the open-source site database (https://doi.org/10.5880/GFZ.2.1.2020.006) and can be provided upon request in this stage.

\section{ACKNOWLEDGEMENTS}

We thank the National Research Institute for Earth Science and Disaster Prevention (NIED), Japan and the Garner Valley Downhole Array (GVDA), California, as well as Lanzano, G., L. Luzi, E. Russo, C. Felicetta, M. C. D'Amico, S. Sgobba and F. Pacor (2018) for making their data available. We acknowledge the China Strong Motion Network Center (CSMNC) for providing the Chinese strong-motion data. The first author appreciates the discussion with Sreeram Kotha. We thank the very constructive feedback from Adrian Rodriguez-Marek and an anonymous reviewer whose suggestions greatly help improve our work. 


\section{REFERENCES}

Abrahamson, N. A., Silva, W. J. \& Kamai, R., 2014. Summary of the Abrahamson, Silva, and Kamai NGA-West2 ground-motion relations for active crustal regions, Earthq. Spectra, 30, 1025-1055.

Al Atik, L., 2015. NGA-East: Ground-Motion Standard Deviation Models for Central and Eastern North America, PEER Report No. 2015/07 Pacific Earthquake Engineering Research Center, University of California, Berkeley.

Al Atik, L., Abrahamson, N., Bommer, J. J., Scherbaum, F., Cotton, F. \& Kuehn, N., 2010. The variability of ground-motion prediction models and its components. Seismol. Res. Lett., 81, 794-801.

Atkinson, G. M., 2006. Single-station sigma, Bull. seism. Soc. Am., 96, 446-455.

Bard, P. Y., 1999. Microtremor measurements: a tool for site effect estimation? in Proceedings of the 2nd International Symposium on the Effects of Surface Geology on Seismic Motion, Yokohama, Japan, Vol. Irikura, Kudo, Vol. 3, pp. 1251-1279, Okada\& \& Sasatani, Balkema.

Bindi, D., Spallarossa, D. \& Pacor, F., 2017. Between-event and betweenstation variability observed in the Fourier and response spectra domains: comparison with seismological models. Geophys. J. Int., 210, 1092-1104.

Bonilla, L. F. \& Ben-Zion, Y., 2021. Detailed space-time variations of the seismic response of the shallow crust to small earthquakes from analysis of dense array data. Geophys. J. Int., 225, 298-310.

Boore, D. M., Stewart, J. P., Seyhan, E. \& Atkinson, G. M., 2014. NGAWest2 equations for predicting PGA, PGV, and 5\% damped PSA for shallow crustal earthquakes, Earthq. Spectra, 30, 1057-1085.

Bowden, D. C. \& Tsai, V. C., 2017. Earthquake ground motion amplification for surface waves. Geophys. Res. Lett., 44, 121-127.

Campbell, K. W. \& Bozorgnia, Y., 2019. Ground motion models for the horizontal components of arias intensity (AI) and cumulative absolute velocity (CAV) using the NGA-West2 database. Earthq. Spectra, 35, $1289-1310$

Dawood, H. M., Rodriguez-Marek, A., Bayless, J., Goulet, C. \& Thompson, E., 2016. A flatfile for the KiK-net database processed using an automated protocol. Earthq. Spectra, 32, 1281-1302

Douglas, J. \& Edwards, B., 2016. Recent and future developments in earthquake ground motion estimation. Earth Sci. Rev., 160, 203-219.

Hassani, B. \& Atkinson, G. M., 2020. Equivalent point-source groundmotion model for subduction earthquakes in Japan. Bull. seism. Soc. Am., 111, 951-974.

Kaklamanos, J. \& Bradley, B.A., 2018. Challenges in predicting seismic site response with 1D analyses: conclusions from $114 \mathrm{KiK}$-net vertical seismometer arrays. Bull. seism. Soc. Am., 108, 2816-2838.

Kawase, H., Sánchez-Sesma, F.J. \& Matsushima, S., 2011. The optimal use of horizontal-to-vertical spectral ratios of earthquake motions for velocity inversions based on diffuse-field theory for plane waves. Bull. seism. Soc. Am., 108, 2001-2014.

K. \& Ohmachi, T., 1998. Ground-motion characteristics estimated from spectral ratio between horizontal and vertical components of microtremor. Bull. seism. Soc. Am., 88, 228-241.

Kotha, S. R., Cotton, F. \& Bindi, D., 2018. A new approach to site classification: mixed-effects ground motion prediction equation with spectral clustering of site amplification functions. Soil Dyn. Earthq. Eng., 110, 318-329.

Ktenidou, O. J., Chávez-García, F. J., Raptakis, D. \& Pitilakis, K. D, 2016. Directional dependence of site effects observed near a basin edge at Aegion, Greece. Bull. Earthq. Eng., 14, 623-645.

Ktenidou, O. J., Roumelioti, Z., Abrahamson, N., Cotton, F., Pitilakis, K. \& Hollender, F.., 2018. Understanding single-station ground motion variability and uncertainty (sigma): lessons learnt from EUROSEISTEST. Bull. Earthq. Eng., 16, 2311-2336.

Kwak, D. Y. \& Seyhan, E.. 2020. Two-stage nonlinear site amplification modeling for Japan with VS30 and fundamental frequency dependency, Earthq. Spectra, 36. 1359-1385.

Lanzano, G. et al., 2019. The pan-European Engineering Strong Motion (ESM) flatfile: compilation criteria and data statistics. Bull. Earthq. Eng., $17,561-582$.
Lanzano, G., Pacor, F., Luzi, L., D’Amico, M.C., Puglia, R. \& Felicetta, C., 2017. Systematic source, path and site effects on ground motion variability: the case study of Northern Italy. Bull. Earthq. Eng., 15, 45634583.

Lin, P.-S., Chiou, B., Abrahamson, N., Walling, M., Lee, C.-T. \& Cheng, C.-T., 2011. Repeatable source, site, and path effects on the standard deviation for empirical ground-motion prediction models. Bull. seism. Soc. Am., 101, 2281-2295.

Matsushima, S., Kosaka, H. \& Kawase, H., 2017. Directionally dependent horizontal-to-vertical spectral ratios of microtremors at Onahama, Fukushima, Japan. Earth Planets Space, 69, 96.

Maufroy, E. et al., 2017. Source-related variability of site response in the Mygdonian basin (Greece) from accelerometric recordings and 3D numerical simulations. Bull. seism. Soc. Am., 107, 787-808.

Morikawa, N., Kanno, T., Narita, A., Fujiwara, H., Okumura, T., Fukushima, Y. \& Guerpinar, A., 2008. Strong motion uncertainty determined from observed records by dense network in Japan. J. Seismol., 12, 529-546.

Nakamura, Y., 1989. A method for dynamic characteristics estimation of subsurface using microtremor on ground surface, Q. Rep. Railway Tech. Res. Inst., 30, 25-33.

Nakamura, Y., 2019. What is the Nakamura method? Seismol. Res. Lett., 90, $1437-1443$

National Research Institute for Earth Science and Disaster Resilience, 2019. NIED K-NET, KiK-net, National Research Institute for Earth Science and Disaster Resilience, doi:10.17598/NIED.0004.

Pilz, M., Parolai, S., Leyton, F., Campos, J. \& Zschau, J., 2009. A comparison of site response techniques using earthquake data and ambient seismic noise analysis in the large urban areas of Santiago de Chile. Geophys. J. Int., 178, 713-728.

Rodríguez-Marek, A., Cotton, F., Abrahamson, N. A., Akkar, S., Al Atik, L., Edwards, B., Montalva, G. A. \& Dawood, H., 2013. A model for singlestation standard deviation using data from various tectonic regions. Bull. seism. Soc. Am., 103, 3149-3163.

Rodríguez-Marek, A., Montalva, G., Cotton, F. \& Bonilla, F., 2011. Analysis of single-station standard deviation using the KiK-net data. Bull. seism. Soc. Am., 101, 1242-1258.

Roumelioti, Z., Hollender, F. \& Guéguen, P., 2019. Rainfall-induced variation of seismic waves velocity in soil and implications for soil response: what the ARGONET (Cephalonia, Greece) vertical array data reveal. Bull. seism. Soc. Am., 110, 441-451.

Schober, P., Boer, C. \& Schwarte, L. A., 2018. Correlation coefficients: appropriate use and interpretation. Anesth. Analg., 126, 1763-1768.

Stewart, J. P. \& Afshari, K., 2020. Epistemic uncertainty in site response as derived from one-dimensional ground response analyses. J. Geotech. Geoenviron. Eng., 147(1),

Stewart, J. P., Afshari, K. \& Goulet, C. A., 2017. Non-ergodic site response in seismic hazard analysis. Earthq. Spectra, 33, 1385-1414.

Uebayashi, H., Kawabe, H. \& Kamae, K., 2012. Reproduction of microseism $\mathrm{H} / \mathrm{V}$ spectral features using a three-dimensional complex topographical model of the sediment-bedrock interface in the Osaka sedimentary basin. Geophys. J. Int., 189, 1060-1074.

Vyas, J. C., Mai, P. M. \& Galis, M. 2016. Distance and Azimuthal Dependence of Ground-Motion Variability for Unilateral Strike-Slip Ruptures, Bull. seism. Soc. Am., 106, 1584-1599.

Wang, S. Y. et al., 2021. Near-surface softening and healing in eastern Honshu associated with the 2011 magnitude-9 Tohoku-Oki Earthquake. Nat. Commun., 12, 1215.

Weatherill, G., Kotha, S. R. \& Cotton, F., 2020. Re-thinking site amplification in regional seismic risk assessment. Earthq. Spectra, 36, 274-297.

Wirth, E. A., Vidale, J. E., Frankel, A. D., Pratt, T. L., Marafi, N. A., Thompson, M. \& Stephenson, W. J., 2019. Source-dependent amplification of earthquake ground motions in deep sedimentary basins. Geophys. Res. Lett., 46, 6443-6450.

Zhao, J. X. \& Zhang, J., 2010. Side-effect of using response spectral amplification ratios for soft soil sites-earthquake source-type dependent amplification ratios. Soil Dyn. Earthq. Eng., 30, 258-269. 
Zhao, J. X., Zhang, J. \& Irikura, K., 2009. Side effect of using response spectral amplification ratios for soil sites - variability and earthquakemagnitude and source-distance dependent amplification ratios for soil sites. Soil Dyn. Earthq. Eng., 29, 1262-1273.

Zhu, C, Weatherill, G., Cotton, F., Pilz, M., Kwak, D. Y \& Kawase, H., 2021. An open-source site database of strong-motion stations in Japan: K-NET and KiK-net (v1.0.0). Earthq. Spectra., 37, 2126-2149.

Zhu, C., Pilz, M. \& Cotton, F., 2019. Which is a better proxy, site period or depth to bedrock, in modelling linear site response in addition to the average shear-wave velocity? Bull. Earthq. Eng., $1-24$.

Zhu, C., Pilz, M. \& Cotton, F., 2020. Evaluation of a novel application of earthquake HVSR in site-specific amplification estimation. Soil Dyn. Earthq. Eng., 139, doi:10.1016/j.soildyn.2020.106301.

\section{SUPPORTING INFORMATION}

Supplementary data are available at $G J I$ online.

Figure $\mathbf{S} 1 \sigma_{\mathrm{HV}, \mathrm{s}}$ of HVSR at accelerometers $0-5$ and $\sigma_{\mathrm{SB}, \mathrm{s}}$ of SBSR from the ground surface to various depths at the Garner Valley Downhole Array (GVDA).
Figure S2. Difference between $\sigma_{\mathrm{HV}}$ using (5 per cent-damped) PSA- and smoothed FAS-based HVSRs at each of the $207 \mathrm{KiK}-\mathrm{net}$ sites (the same as used in Fig. 1). FAS is smoothed using KonnoOhmachi window with smoothing coefficient (a) $b=20$, and (b) $b=40$. Dots denote the mean differences, and crosses represent the mean \pm 1 std range. (c) Comparison of the average differences using different degrees of smoothing.

Figure S3. Pearson's correlations between site parameters $\left(V_{\mathrm{S} 30}\right.$, $f_{\mathrm{P}, \mathrm{HV}}$, Roughness and $Z_{2.5}$ in $\ln$ scales) and $\sigma_{\mathrm{HV}, \mathrm{s}}(\operatorname{lnFAS})$ at different oscillator frequencies.

Figure S4. $\sigma_{\mathrm{HV}}(\operatorname{lnFAS})$ for $16 M_{\mathrm{JMA}}$ - and $R_{\text {epic }}$-bins using K-NET and $\mathrm{KiK}-$ net data. Each line corresponds to one bin.

Figure S5. $\sigma_{\mathrm{HV}, \mathrm{s}}(\mathrm{lnFAS})$ using microtremors collected in the large urban area of Santiago de Chile. The solid black line corresponds to the mean, and the dashed lines represent the mean \pm 1 std range. Table S1. $\sigma$ HV (lnFAS) and its standard deviation derived using $697 \mathrm{KiK}-n e t$ and $1169 \mathrm{~K}-\mathrm{NET}$ sites

Table S2. $\sigma$ HV (lnFAS) for 16 magnitude (MJMA)- and hypocentral distance (Repic, unit: km)-bins using K-NET and KiK-net data 